NBER WORKING PAPER SERIES

\title{
DID IMPROVEMENTS IN HOUSEHOLD TECHNOLOGY CAUSE THE BABY BOOM? EVIDENCE FROM ELECTRIFICATION, APPLIANCE DIFFUSION, AND THE AMISH
}

\author{
Martha J. Bailey \\ William J. Collins \\ Working Paper 14641 \\ http://www.nber.org/papers/w14641
}

\section{NATIONAL BUREAU OF ECONOMIC RESEARCH 1050 Massachusetts Avenue \\ Cambridge, MA 02138}

Bailey is an Assistant Professor of Economitinuaffe 2909 alty Affiliate at the Population Studies and National Poverty Centers at the University of Michigan, and a Faculty Research Fellow at the National Bureau of Economic Research. Collins is a Professor of Economics at Vanderbilt University and a Research Associate of the National Bureau of Economic Research. We are grateful to Soren Anderson, John Bound, Alison Buttenheim, Charlie Brown, John DiNardo, Robert Driskill, Richard Easterlin, Daniel Eisenberg, Robert Gordon, Chris House, Karen Johnson-Weiner, Miles Kimball, David Lam, Robert Margo, Elyce Rotella, Katharine Shester, Matthew Shapiro, Jeff Smith, and Gary Solon for useful comments and suggestions. We also thank participants in seminars at Clemson University, the CSWEP Junior Faculty Mentoring Workshop, the Economic History Association Meetings, Lehigh University, McGill University, the National Bureau of Economic Research, the Population Association of America's Meetings, Queen's University, the University of Michigan (Economic History, Macroeconomics, and Population Studies), University of North Carolina-Greensboro, and the University of Toronto. Emily Boleman, Emily Gray, and Brad Hershbein provided outstanding research assistance. We gratefully acknowledge financial support from the National Science Foundation and the Robert Wood Johnson Foundation and helpful comments from Ananth Seshadri and Guillaume Vandenbroucke. The views expressed herein are those of the author(s) and do not necessarily reflect the views of the National Bureau of Economic Research.

NBER working papers are circulated for discussion and comment purposes. They have not been peerreviewed or been subject to the review by the NBER Board of Directors that accompanies official NBER publications.

(C) 2009 by Martha J. Bailey and William J. Collins. All rights reserved. Short sections of text, not to exceed two paragraphs, may be quoted without explicit permission provided that full credit, including (c) notice, is given to the source. 
Did Improvements in Household Technology Cause the Baby Boom? Evidence from Electrification, Appliance Diffusion, and the Amish

Martha J. Bailey and William J. Collins

NBER Working Paper No. 14641

January 2009, Revised June 2010

JEL No. E0,J1,N3

\begin{abstract}
More than a half century after its peak, the baby boom's causes remain a puzzle. A new argument posits that rapid advancements in household technology from 1940 to 1960 account for this large increase in fertility. We present new empirical evidence that is inconsistent with this claim. Rapid advances in household technology began long before 1940 while fertility declined; differences and changes in appliance ownership and electrification in U.S. counties are negatively correlated with fertility rates from 1940 to 1960; and the correlation between children ever born (measured at ages 41 to 60) and access to electrical service in early adulthood is negative for the relevant cohorts of women. Moreover, the Amish, a group strictly limiting the use of modern household technologies, experienced a sizable and coincident baby boom. A final section reconciles this evidence with economic theory by allowing households to have utility over home-produced commodities that are substitutes for the number of children.
\end{abstract}

Martha J. Bailey

University of Michigan

Department of Economics

611 Tappan Street

207 Lorch Hall

Ann Arbor, MI 48109-1220

and NBER

baileymj@umich.edu

William J. Collins

Department of Economics

Vanderbilt University

VU Station B \#351819

2301 Vanderbilt Place

Nashville, TN 37235-1819

and NBER

william.collins@vanderbilt.edu 
After at least 100 years of secular decline, births per 1,000 women (ages 15 to 44) in the United States increased by more than 50 percent between 1939 and 1957 (see figure 1). This remarkable departure from longer-term trends, often called the "baby boom,” was not a short-lived, statistical aberration reflecting postponed births from the Depression or World War II. Rather, it stretched over two decades and was driven by earlier marriage and childbearing, shorter birth intervals, and increases in completed childbearing (Ryder 1980, Rogers and O’Connell 1984). ${ }^{1}$ These features of the American baby boom present a fascinating challenge to scholars, especially because the rise in fertility took place against a backdrop of increasing income, urbanization, educational attainment, and women’s labor force participation-all trends typically associated with declining fertility.

For over forty years, two main schools of thought in economics have shaped scholarship on the baby boom. One cornerstone of the literature has been Richard Easterlin's “relative income hypothesis” (1961, 1980), which emphasizes the difference between a cohort's “earnings potential” relative to its "material aspirations." In this view, children who grew up in the Depression and World War II formed modest material aspirations that were far surpassed by their actual experience as young adults in the 1940s and 1950s. They responded by marrying younger and having more children. Another cornerstone has been Gary Becker’s neoclassical theory of fertility $(1960,1965$, with Gregg Lewis 1973). Contrary to Easterlin’s emphasis on preference formation, the neoclassical viewpoint emphasizes changes in relative prices and incomes. Robert Barro and Becker (1988) reformulated this static framework to allow altruistic parents to incorporate their children's utility within an inter-generational, dynastic framework. Their paper argues that a temporary increase in child-rearing costs during the Great Depression and World War II depressed fertility and that the postwar baby boom made up for these foregone births (1988: 15). ${ }^{2}$ Although the Easterlin and Becker schools of thought have moved closer together with time (Sanderson 1976), the literature has not reached consensus on the ultimate causes of the baby boom.

In a recent contribution, Greenwood, Seshadri, and Vandenbroucke (2005, henceforth GSV) advance a new and specific price-based explanation for the baby boom. In an overlappinggenerations framework, they argue that a burst in the productivity of household technology led to a

\footnotetext{
${ }^{1}$ Completed cohort fertility (measured at ages 41 to 61 ) is plotted with period fertility in figure 1 . Women born during the 1930s, the mothers of the "baby boomers," had completed fertility rates as high as women born in the late nineteenth century.

${ }^{2}$ To be clear, the proposed Barro-Becker mechanism is not within-cohort inter-temporal substitution of births. Rather, the interpretation is that inter-temporal substitution occurs across cohorts as dynastic families substitute childbearing to generations when child-rearing costs are low.
} 
reduction in the shadow price of childbearing and, therefore, to a pronounced rise in fertility between 1940 and 1960.

This paper examines the empirical content of the household-productivity explanation of the baby boom by drawing on an array of historical and empirical evidence. First, we present direct evidence on the timing of the diffusion of modern household technologies, which began in earnest decades before the baby boom and continued afterwards. Because growth in total factor productivity was exceptionally rapid during the 1940 to 1960 period (leading to an increase in wages and increasing the opportunity cost of childrearing), it is difficult to square these time-series with a relative burst of productivity in the household sector.

Because heterogeneity in the opportunity cost of childbearing might obscure the hypothesized positive relationship between household technology and childbearing, we next examine links between fertility and modern household technologies at the county-level in 1940, 1950 and 1960. Unconditional correlations, partial correlations from models using state fixed effects, and partial correlations from regressions with multiple covariates in both cross-sectional and firstdifferenced specifications fail to support the household-productivity hypothesis. Furthermore, the absence of a positive relationship does not appear to reflect differences in the timing of childbirth. Using census data on completed fertility (the number of children ever born by ages 41 to 60) and exposure to electrical service in early adulthood, time-series and regression evidence exhibits a negative (not a positive) relationship.

A final piece of evidence comes from the demographic history of the Old Order Amish. During the 1940s and 1950s, the Old Order Amish strictly limited their use of modern appliances on religious grounds, and therefore, remained isolated from these technology-induced gains in household productivity. If new household technologies caused the baby boom, as hypothesized, then fertility change among the Amish should have been relatively small during this period. We present evidence from the U.S. census that the Amish, in fact, had a rise in fertility that began at nearly the same time, lasted just as long, and was approximately as large as the baby boom in the rest of the U.S. population. These findings are corroborated by independent studies of genealogical records that show a sizable increase in fertility among the Old Order Amish at the same time as the U.S. baby boom.

In summary, none of our three approaches supports the household-productivity explanation of the U.S. baby boom. The paper's final section interprets our findings using the Slutsky equation and discusses their implications for other explanations for the baby boom. We conclude that more 
than a half century after its peak, the ultimate causes of the baby boom remain one of the twentieth century’s great puzzles.

\section{The Diffusion of Household Technology in the First Half of the Twentieth Century}

The household-productivity explanation of the baby boom requires an anomalous burst of technological progress in the household sector between 1940 and 1960. Measurement problems inherent to both household production and new durable goods make it difficult to assess the plausibility of such a burst quantitatively and directly, but several pieces of evidence cast doubt on this interpretation of history.

Figure 2 illustrates the pattern of household appliance adoption from 1890 to 1970. Rather than combining series into an index, figure 2 plots them separately to highlight the timing of diffusion for different technologies. Although it is clear that improved household technologies diffused between 1940 and 1960, it is far less clear that the pace of progress accelerated relative to previous decades. Rather, in the decades before the baby boom, households rapidly adopted indoor plumbing, electricity, electric irons, washing machines, refrigerators, modern stoves, modern lighting, and vacuum cleaners.

In 1890, only 24 percent of homes had running water and 13 percent had flush toilets; only 3 percent of homes had electrical service in 1900, and essentially none had mechanical refrigerators, washing machines, or vacuum cleaners (Lebergott 1993: 101, 102, 113). By 1940, the census reported that approximately 70 percent of households had running water, 60 percent had a private flush toilet, 79 percent had electrical lighting and nearly as many had electric irons, ${ }^{3} 44$ percent had mechanical refrigerators, 54 percent had gas or electric stoves (rather than wood, coal, or kerosene), and 42 percent had central heating (Brunsman and Lowery 1943). We estimate that between 40 and 50 percent had power-driven washing machines in $1940 .^{4}$ The overwhelming impression in figure 2 is that a strong upward trend in household production technology preceded the baby boom by at least three decades.

Historical scholarship cites early advances in other aspects of home production technology as well-improvements in stoves and the distribution of processed foods, including canned goods, refrigerated and preserved meat, and ready-to-eat cereals, transformed meal preparation during the

\footnotetext{
${ }^{3}$ Lebergott estimates that 65 percent of homes owned electric irons in 1932, whereas about 68 percent had electrical lighting in 1930 (1976: 280, 288).

${ }^{4}$ The higher estimate (48 percent) is from multiplying figures for clothes washer ownership in 1940 among "wired" households (61 percent) from Bowden and Offer (1994: 745) by the proportion of occupied dwellings with electrical lighting (79 percent) from the U.S. Census (as reported in Brunsman and Lowery 1943: 91). The lower estimate (43 percent) is from using an alternative measure of "wired" houses (71 percent) from Bowden and Offer (1994).
} 
nineteenth and early twentieth centuries (Giedion 1948, Strasser 1982, Cowan 1983, Harris 2008). Cowan writes, "By the turn of the century, canned goods were a standard feature of the American diet: women's magazines contained advertisements for them on nearly every page, standard recipes routinely called for them, and the weekly food expenditures of even the poorest urban families regularly included them” (1983: 73). Sewing machines diffused widely after 1850 (Godley 2001). Christine Frederick's widely circulated writings (1912) on how to improve efficiency in household work were published decades before the baby boom and were a continuation of a literature that dates to the mid-nineteenth century work of Catharine Beecher (1841). After 1960, automatic dishwashers, clothes dryers, air-conditioning, and microwaves were recasting patterns of housework yet again (Cox and Alm 1997: 22).

Price series for goods used in household production reinforce the notion that home productivity was rising long before the baby boom. Nordhaus (1997) shows that the price of light fell from an index value of 10.0 in 1900 to 0.7 by 1940 when expressed relative to a consumer price index; he reports a decline from 0.220 in 1900 to 0.005 in 1940 when expressed relative to average earnings. ${ }^{5}$ The price of residential electricity also fell rapidly in the first 40 years of the century (U.S. Department of Commerce 1975, series S-116). Rees (1961) constructs price indices for clothing and home furnishings (in which stoves get the largest weight) from 1890 to 1914, and these, too, show sizable declines.

Still, the steady diffusion of modern household technologies in the early twentieth century may be consistent with a burst of relative progress in household productivity if there were a midcentury slowdown in market sector technological advance. But this was not the case according to our best estimates of twentieth-century total factor productivity (TFP) trends. Gordon (2000: 51) suggests that TFP growth peaked in the 1950-1964 period, followed closely in magnitude by the 1928-1950 period. He estimates that both periods registered higher growth rates than any other since 1870. Field challenges the primacy of the 1950-1964 period, but not the idea that productivity growth was at an historically high level during the baby boom. He pushes emphasis back to the 1930s, noting that technological advances in the 1930s provided "the basis for much of the labor and multifactor productivity improvements of the 1950s and 1960s” (2003: 1399). GSV cite estimates of TFP growth of 1.41 percent per year from 1900 to 1948 and 1.68 percent per year from 1948 to 1974

\footnotetext{
${ }^{5}$ The price of light continued to decline after 1940, but not in manner that suggests an increase in the pace of technological change in the baby boom years. Comparable quality-adjusted price data for other goods is scarce prior to 1940, but Raff and Trajtenberg (1997) report large declines in the quality-adjusted price of automobiles relative to other goods, which would effectively lower the cost of home-produced transport services.
} 
(2005: 189, citing U.S. Bureau of Census 1975, Series W6, which is based on Kendrick (1961), and U.S. Bureau of Labor Statistics). Because all of these sources conclude that the market-sector productivity growth rate increased during the baby boom period, the argument for a relative acceleration of household technology is even more difficult to sustain than the argument for an absolute increase in the rate of household productivity growth.

Wage trends in figure 3 provide yet another way to characterize productivity growth in the market sector. ${ }^{6}$ As with TFP, there is no evidence of a slowdown in real wage growth in the baby boom period. We calculate an average growth rate of 2.7 percent from 1940 to 1960, compared to 2.5 percent from 1920 to 1940, and 1.7 percent from 1900 to 1920.

It is difficult to create comprehensive long-run price series that accurately capture changes in durable goods’ quality (Griliches 1971, Bresnahan and Gordon 1997), and unadjusted price and quantity series from the national accounts may contain sizable biases that cannot be differenced out by expressing one series relative to another (Gordon 1990). With these caveats, figure 4 presents Gordon’s (1990) quality-adjusted price series for consumer durables relative to producer durables (first available after 1947) alongside the Bureau of Economic Analysis (BEA) series which reaches back further in time but is not adjusted for quality. (Appendix 1 provides a more detailed discussion of the available time-series evidence from both sources). Although the quality-adjusted Gordon data are probably preferable to the BEA data, they do not begin early enough to characterize the pre-war period. Taking the BEA data series at face value, it appears that the baby boom took off in the 1940s despite a jump in the relative price of consumer durables and household appliances that kept relative prices high until at least 1950. The relative price of consumer durables returned to its pre-war value by 1955, but fertility increased much less in the 1950s than in the 1940s. If the BEA series is correct in suggesting a sharp rise in the relative price of goods used in household production during World War II, then the modest decline in the Gordon series in the late 1940s may reflect a return-to-trend rather than an unprecedented rate of advance.

The national-level time-series reviewed in this section do not evince a straightforward relationship between the baby boom and changes in household technology. Rather than a large and coincident 20-year burst of productivity growth in home productivity, it appears that household technology improved and diffused gradually before, during, and after the baby boom. Moreover, progress in household productivity between 1940 and 1960 was rivaled by unprecedented and

\footnotetext{
${ }^{6}$ Our real wage index follows Margo (2006: 2-44). The nominal wage index for unskilled labor is series Ba4218 and the cost of living series is Cc2 (from Carter et al. 2006, based on David and Solar 1977).
} 
unsurpassed rates of growth in market productivity, which should have tended to depress fertility. Because national time-series data may mask important changes and variation in opportunity costs associated with childrearing and households' capacity to upgrade home technologies, the following sections use more detailed data to shed light on the credibility of the household-productivity hypothesis.

\section{Appliance Ownership, Electrification, and Fertility in Disaggregated Data}

This section uses a newly-compiled, county-level panel dataset for the United States to examine the household-technology hypothesis directly. To create this dataset, we encoded countylevel appliance ownership counts from the census volumes for the 1940 to 1960 period; these data are supplemented by publicly-available, county-level economic and demographic information (Haines 2004). The resulting dataset contains approximately 3,000 counties (Hawaii and Alaska are excluded) for 1940, 1950 and $1960 .^{7}$

Our measure of the general fertility rate is the number of infants (under age one) per 1,000 women of ages 15 to 44 . The level of household technology is measured as the proportion of housing units with refrigerators, washing machines, modern stoves (e.g., fueled by electricity or gas, rather than coal, wood, or kerosene), and electrical lighting. The census data provide a geographically detailed view of the diffusion of modern appliances during the baby-boom period, but the census did not collect information on every appliance in each year. Electrical service and refrigerators were reported in 1940 and 1950, washing machines only in 1960, and cooking fuel (an indicator of modern stoves) in 1940, 1950, and 1960 (see appendix 2 for more detail on data sources).

Table 1 reports means and standard deviations for each of our measures. Consistent with figure 2, our data shows that the diffusion of electrical service and modern appliances was widespread. The data provide new information about the differential timing of technology adoption across counties. For instance, the increase in electrical service over the 1940s ranges from slow (an increase of roughly 8 percentage points at the 10th percentile) to rapid (49.8 at the $90^{\text {th }}$ percentile). From 1940 to 1960, the same is true for modern stoves: ownership rates rose by 35.2 percentage points at the $10^{\text {th }}$ percentile but by 84.9 at the $90^{\text {th }}$ percentile. There is great variation in the magnitude of the baby boom as well. Although more than 95 percent of counties recorded an

\footnotetext{
${ }^{7}$ Consistent data on household appliances are unavailable in the micro-level IPUMS samples. The 1940 and 1950 public-use micro data samples do not include any information on household appliances. The 1960 micro data sample includes information on washers, dryers, and freezers, but does not reveal geographic information below the state level.
} 
increase in fertility between 1940 and 1960, the size of the baby boom (in terms of our measure of the general fertility rate) ranged from 11.3 at the $10^{\text {th }}$ percentile to 66.1 at the $90^{\text {th }}$ percentile.

\section{Cross-Sectional Regressions}

Our analysis uses the intertemporal and geographic variation in these measures within the following linear regression framework,

$$
F_{j s}=\tau A_{j}+\boldsymbol{\beta} \boldsymbol{X}_{j}+\sum_{k=1}^{49} \gamma_{k} 1(s=k)+\varepsilon_{j s},
$$

where $F$ is the fertility rate in county $j$ and state $s, A$ is our measure of the state of household technology, and 1( ) is a state dummy variable. Covariates in $\boldsymbol{X}$ include median years of schooling for those over age 24 , log of median property value for owner-occupied housing, log of median family income (in 1950 and 1960 only due to data constraints), racial composition, measures of local economic development (the proportion working in agriculture, the proportion working in manufacturing, the urban proportion of the county's current population, and log population density), and a correlate of the opportunity cost of childrearing (the proportion of women in the labor force).

Table 2 reports least-squares estimates of $\tau$ separately for 1940, 1950 and 1960. Each point estimate is from a separate, unweighted regression of the general fertility rate on appliance ownership. ${ }^{8}$ Heteroskedasticity-robust standard errors are corrected for correlation within states and presented in brackets below each point estimate. The specification in column 1 includes no covariates or fixed effects, and the unadjusted correlations between fertility and appliance ownership (refrigerators, modern stoves, and washing machines) are strongly negative. These correlations are depicted in the scatterplots of figure 5: panel A plots county-level fertility rates against appliance ownership for 1940, and panels B and C plot data for 1950 and 1960, respectively. None shows a positive relationship between fertility and these technologies.

One reason for the negative correlations might be unobserved heterogeneity in workers' labor market productivity. For example, wages may be positively correlated with appliance ownership and negatively correlated with fertility. Omitting such variables from the regression may induce a negative bias in the point estimate of interest. To reduce the scope for this source of omitted variable bias, column 2 includes state fixed effects —-which adjusts for average differences in wages or other unobservables across states-and column 3 adds the full set of county-level demographic and economic covariates described above. Identifying $\tau$ from within-state variation in appliance ownership and fertility (column 2) tends to increase the magnitude of the point estimates slightly.

\footnotetext{
${ }^{8}$ Results from quantile regressions at the median, which are less sensitive to outliers than OLS, yield results that are qualitatively similar to the OLS estimates reported in tables 2, 3 and 4 . See web appendix 3.
} 
Adding controls for county-level characteristics (column 3) results in point estimates that are smaller in magnitude, but none of the six estimates is positive and statistically significant. ${ }^{9}$ Moreover, the largest point estimate (0.068 on washing machines in 1960) in conjunction with a 30 percentage point increase in washing machine ownership (the change in national average in figure 2) implies an increase of 2.0 infants per 1,000 women ages 15 to 44. Even using the upper bound of the 95 percent confidence interval implies an increase of only 6.2 infants. Because the baby boom entailed an increase of about 45 infants per 1,000 women, the magnitude of this exceptional point estimate, even at the outer reaches of its confidence interval, is not consistent with the hypothesis that appliance diffusion caused the baby boom.

As an additional sensitivity check, we used the percentage of households with electrical lights to instrument for modern appliance ownership in the fertility regressions for 1940 and 1950 (years in which the census documented electrical lighting). The results show negative point estimates on appliance ownership in every case. Having access to electricity was a binding constraint on the use of many modern technologies, but it is difficult to establish that electrification is excludable from the fertility equation, and it is possible that an association between the instrumental variable and the omitted variables of concern may bias the estimates. For instance, local electrification initiatives may have affected households' adoption of technology and local economic development. With these caveats in mind, readers may refer to appendix 3 to see the detailed results and weigh the evidence.

\section{First-Differenced Regressions}

Although our covariates are fairly exhaustive, one potential problem with the cross-sectional regressions is that unobserved differences in the demand for children may influence both appliance ownership and fertility outcomes. For instance, counties with permanently higher opportunity costs of childbearing that are not captured by the control variables may adopt appliances first and also have lower fertility rates. To account for these unobserved differences, we estimate first-differenced regressions. ${ }^{10}$ First-differenced specifications eliminate time-invariant, unobservable county-level differences that may be correlated with the timing of technology adoption and the baby boom,

\footnotetext{
${ }^{9}$ For 1950 and 1960, in addition to the control for median income, we can add control variables for the proportion of families with low income (below $\$ 2,000$ in 1950 or $\$ 3,000$ in 1960) and high income (above \$5,000 in 1950 or above $\$ 10,000$ in 1960) to capture differences in the income distribution. The additional controls have a small effect on the coefficients and standard errors reported in table 2. We cannot use the IPUMS data to calculate even richer county-level characterizations of the income distribution because county codes are not revealed in the 1950 or 1960 public use samples. There is no family income variable for 1940 .

${ }^{10}$ Suppose the household productivity hypothesis is correct, but that in cross sections unobserved opportunity costs obscure the true positive relationship between appliances and fertility. New appliances are quickly adopted in the
} 


$$
\Delta F_{j s}=\tau^{D} \Delta A_{j s}+\widetilde{\boldsymbol{\beta}} \Delta \boldsymbol{X}_{j s}+\sum_{k=1}^{49} \tilde{\gamma}_{k} 1(s=k)+u_{j s}
$$

where $\Delta$ denotes county-level changes in the variable over a 10 or 20 year period (either from 1940 to 1950,1950 to 1960 , or 1940 to 1960 ), and the remaining notation is as previously described. In this specification, observed, time-varying county characteristics (including changes in women's labor market participation rates) are captured in $\Delta \boldsymbol{X}^{11}{ }^{11}$ and the effects of unobserved, fixed differences are differenced out by design. State fixed effects now absorb unobserved changes at the state level, such as changes in perceived prosperity, policy, or other relevant conditions that may otherwise bias the point estimates. County-level, unobservable shocks that are correlated with changes in appliance ownership and fertility are the primary source of potential bias for the coefficient of interest. ${ }^{12}$

Table 3 reports unweighted, least-squares estimates of $\tau^{D}$ for three specifications. Column 1 presents correlations from a specification with no covariates, column 2 includes state fixed effects, and column 3 includes $\Delta \boldsymbol{X}$ s for pairs of census years with information on the same appliance measures (1940 to 1950, 1950 to 1960, or 1940 to 1960). As in table 2, heteroskedasticity-robust standard errors are computed and corrected for correlation within states for all specifications reported. The unadjusted correlations between appliance and fertility changes are negative, as shown in column 1 and in the scatterplots of figure 6 . The within-state correlations are also negative (column 2). When we account for observable changes in county-level covariates (including women's labor-force participation), unobservable state-level changes, and time-invariant county-level unobservable characteristics (column 3), the estimates are still negative. ${ }^{13}$ If anything, the first-

high-opportunity-cost counties, and fertility there rises from a low initial level. New appliances are not adopted in the low-opportunity-cost counties until later, and, therefore, fertility does not rise until later. In cross-sectional regressions, the strong positive correlation between appliance adoption and wages and negative correlation between wages and fertility might lead to a negative point estimate. If this were the case, however, changes in fertility would be positively correlated with changes in appliance ownership even if the cross sectional relationship between the level of appliance ownership and level of fertility is negative.

${ }^{11}$ Because median family income is unobservable in 1940, differenced regressions with 1940 cannot include the change in log median family income as a control variable. However, it can be included in panel C of table 3 (195060 difference), in which case it slightly strengthens the negative coefficient $(-0.053$, s.e. $=0.055)$. Adding controls for the changes in the proportions of families with low and high income levels further strengthens the negative coefficient $(-0.097$, s.e. $=0.061)$. Given the available census categories, "low income" denotes below $\$ 2,000$ in 1950 and below \$3,000 in 1960; "high income" denotes above \$5,000 in 1950 and above \$10,000 in 1960.

${ }^{12}$ Omitting the control variable for observed changes in women's labor market participation has a small effect on the coefficients of interest in table 3. This suggests that the scope for bias from unobservable changes in women's market opportunities may be small relative to what one would need to account for the baby boom.

${ }^{13}$ For brevity, we omit one set of results (1940-50 change in modern stoves) in which the estimate in column 3 is positive but statistically insignificant $(0.083$, s.e. $=0.052)$. As before, this estimate is too small to account for a substantial portion of the baby boom. It should also be considered in light of the 1940 to 1960 (panel B) and the 1950 to 1960 (panel C) regressions which exhibit negative point estimates. 
differenced regressions provide evidence that counties with greater growth in appliance ownership experienced smaller increases in their fertility rate.

Similar to above, we used the change in the percentage of households with electrical lights to instrument for the change in appliance ownership to provide an additional sensitivity check. The resulting point estimates on appliance ownership become more negative in the second stage in each case (compared to the OLS results), as reported in web appendix 3. The same caveats that were discussed above apply here, and we leave it to interested readers to weigh the evidence from the instrumental variable regressions.

\section{Electrification as a Measure of Household Technology}

A potential concern with the regressions in tables 2 and 3 is that appliance ownership might be a poor measure of the "state of household technology." From the perspective of households, access to electrical service may be a better indicator of the "state of household technology": few families that had electrical service available to them declined to have lights (or electric irons), whereas the decision to purchase specific, large consumer durable goods might have reflected a variety of household-level differences in preferences, prices, and plans. Another advantage of using electrical service is that it is a relatively homogenous and easily comparable product across locations and time.

Our data on county-level electrification come from the published volumes of the Census of Housing in 1950 and from the Haines (2004) county files for $1940 .^{14}$ Panels A and B of table 4 report estimates from separate, unweighted, least-squares regressions using equation 1 , and panel C reports estimates from a regression of the change in the fertility rate on the change in electrical service between 1940 and 1950 using equation 2. Overall, the cross-sectional and first-differenced results provide no evidence of a positive relationship between electrification and fertility. The unconditional correlations are negative and remain so even after accounting for economic and demographic differences and changes in column $3 .{ }^{15}$

Taken together, the results provide no evidence consistent with improvements in household technology causing the baby boom. Whatever caused the baby boom worked against secular economic forces that tended to reduce U.S. fertility rates over this period.

\footnotetext{
14 The census does not report electric lighting in 1960. In 1960 more than 98 percent of homes had electrical service (United States Department of Commerce 1975).

${ }^{15}$ Adding control variables for the proportions of low and high income families to the 1950 regression raises the coefficient from -0.375 to -0.262 ; the standard error falls from 0.083 to 0.066 , so the result is still significantly negative. Family income variables are not available in 1940.
} 


\section{Electrification and Completed Fertility}

A separate matter of concern is that changes in period fertility rates might not adequately reflect changes in completed fertility. For instance, if household technology affects the timing of births in addition to the total number of children, then period measures of fertility (which capture birth timing) would be inadequate measures of lifetime fertility adjustments. If improvements in household productivity induced more childbearing, snapshots of the number of children in households in 1940 and 1950 could miss childbearing that has not yet occurred. Although period rates and completed fertility are highly correlated (see figure 1), we use the Integrated Public Use Microdata Series (IPUMS, Ruggles et al. 2008) to construct completed fertility rates for women ages 41 to 60 in 1980 and 1990. These micro-data are aggregated into birth-state-year-of-birth cells. We then link these estimates of completed fertility with newly-entered data from archived issues of the Edison Electrical Institute's Statistical Bulletin, which contain annual, state-level information on the number of residential electrical service customers from 1925 to 1960. With this information, each woman can be assigned an "electrical service exposure index" based on her year of birth and state of birth, which is the average ratio of electric customers over total households in that state during the time in which the woman would have been at the peak of her childbearing years (ages 15 to 29). ${ }^{16}$ This index is a rough measure of the probability of having access to electricity during the main years of family formation. ${ }^{17}$ It corresponds to the spirit of the GSV model, which assumes that households make decisions about the number of children in the first period of adulthood based upon the current "state of household technology." Given the available data, the index can only be constructed for women born from 1910 (ages 15 to 29 from 1925 to 1939) to 1931 (ages 15 to 29 from 1946 to 1960). The final sample consists of women born in the U.S. between 1910 and 1931 in the 1960 to 1990 IPUMS. $^{18}$

\footnotetext{
${ }^{16}$ We divided the EEI customer counts by the Census of Housing counts of families (1920 and 1930) or occupied dwelling units (1940-1960) in each state to estimate the proportion of families with electrical service. We interpolated the housing counts between census dates. This choice of denominator is consistent with the housing unit counts in Carter et al. (2006). See Kenneth Snowden's discussion (volume 4: 4-500 and 4-501): "Before 1940 the census enumerated 'families' and not housing unit[s].... However, the two concepts are closely related: a census family was defined in 1930 as a single person living alone, a small group of unrelated persons sharing living accommodations, or, more normally, a group of related persons who live together as one household. Despite differences in terminology, therefore, the basic notion of a family, dwelling unit, or housing unit has provided essentially comparable measures of the residential housing stock since 1890."

${ }^{17}$ The median age of last birth for these cohorts was approximately 29.

${ }^{18}$ In the EEI data, Maryland and Washington DC customers are always counted together, and North Carolina and South Carolina customers are often counted together. For consistency we have used these larger units of aggregation for all years, which yields 47 birth state groups. The choice of birth cohorts is due to the fact that completed fertility peaked around the birth cohorts of 1935. Our birth cohorts cover most of the increase in
} 
The hypothesized positive correlation between completed fertility and advances in household technology can be tested by exploiting variation in the timing of electrification in women's state of birth using the following linear regression framework,

$$
N_{y b}=\delta E X P_{y b}+\gamma Z_{y b}+\sum_{k=1}^{46} \mu_{k} 1(b=k)+\sum_{j=1911}^{1931} \theta_{j} 1(j=y)+\varepsilon_{y b},
$$

where $y$ denotes the birth cohort (inferred from age and year of observation) and $b$ denotes the state of birth; $N$ is the mean self-reported number of children ever born (excluding miscarriages and stillbirths); EXP is the "exposure to electricity" index; and $\mu_{k}$ and $\theta_{j}$ capture year-of-birth invariant differences across birth states, $k$, and state-of-birth invariant differences across birth cohorts, $j$,, respectively. The set of demographic controls is limited, because measures of income, place of residence, and other life circumstances at the time of observation in 1960 to 1990 are poor proxies for circumstances in early adulthood. As a result, $\mathbf{Z}$ includes a constant and characteristics that should vary little over the life-course but are strongly correlated with differences in lifetime income and socio-economic status: the proportion of the cohort that is "nonwhite”; mean educational attainment; and, in one specification, the mean of husbands' educational attainment and proportion of husbands who are nonwhite, which are only observed for women residing with their husbands at the time of the census.

Table 5 presents population-weighted least-squares estimates from specifications that add fixed effects and control variables sequentially. Heteroskedasticity-robust standard errors are corrected for correlation within states and are reported in brackets beneath the point estimates. Column 1 presents the unadjusted correlation between children-ever-born and exposure to electricity. Column 2 adds state- and year-of-birth fixed effects. Column 3 includes controls for the woman's race and education level, and column 4 includes her husband's education level (this reduces the sample to women who are currently married at the time of observation). We prefer the specifications that include birth-state and birth-year fixed effects (columns 2 to 4), as they rely upon within-state variation in the speed of electrification to estimate $\delta$. In contrast to the hypothesized positive link between the state of household technology and completed fertility, cohorts born into states with higher rates of electrification in their early adult years had fewer children on average. Regardless of specification, the inclusion of covariates has a negligible impact on the magnitude of the point estimates of interest. Overall, the estimates in table 5 provide evidence that the "state of household technology,” as embodied in electrification, is not positively associated with completed fertility.

completed fertility for the cohorts born between 1920 and 1935 as well as 10 years of cohorts prior to the increase. 
In summary, this section's empirical tests using county-level data with the best available measures of appliance ownership, electrification, and the general fertility rate provide no evidence that advances in household technology caused the baby boom. After controlling for a host of observable characteristics and fixed effects, the point estimates are negative or small in magnitude (table 2, 3, and 4). The negative relationship between exposure to electricity in young adulthood and completed fertility measured at ages 41 to 60 in census data (table 5) also fails to support the claim that advances in household technology caused the baby boom.

\section{Outen the Lights: The Amish Baby Boom}

The regression evidence in section II is informative, but it is subject to potential limitations.

On the one hand, interpretation of a simple partial correlation from a regression specification without covariates may be obscured by cross-sectional heterogeneity or omitted variable bias. On the other hand, controlling for endogenous variables like income - the outcome of a household's labor supply decision that may be correlated with appliance diffusion-may also confound interpretation of the estimates. Adding to these complications, estimating equations described in (1) and (2) may be misspecified because fertility may be a nonlinear function of the "state of household technology" and the present discounted value of lifetime wages_-both unobserved by the econometrician. There is no simple way to deal with these critiques directly.

As an alternative test of the household-productivity hypothesis, we investigate fertility change among a group that limited its use of modern household conveniences and appliances powered by electricity: the Old Order Amish. ${ }^{19}$ In 1963 sociologist John Hostetler wrote, “The most universal of all Amish norms across the United States and Canada are the following: no electricity, telephones, central-heating systems, automobiles, or tractors with pneumatic tires...” (61). The Amish did not completely reject changes in household production technology, but it is clear that the Amish adopted modern appliances much less frequently and much later than the U.S. farm and general populations. ${ }^{20}$ It is also clear that the Amish produced agricultural and craft goods for a broad market of consumers; they were not cut off from the market economy. If rapid improvements in the state of household technology were the main cause of the midcentury baby boom and the Amish were less “treated” with modern household technology, then one would expect a relatively

\footnotetext{
${ }^{19}$ The Amish began settling in Pennsylvania in the early 1700s and later settled in parts of Ohio, New York, Indiana, Illinois, and Ontario. For background on the Amish, see Hostetler (1963) or Nolt (1992).

${ }^{20}$ Hostetler explains, "The social organization of the Amish community has little facility for dealing with change. The general effort to preserve the old and degrade the new is so pervasive that change must occur slowly...” (1963: 306).
} 
small change in Amish fertility. The absence of a baby boom among the Amish, therefore, would be consistent with the household-technology centered explanation of the baby boom. To examine Amish fertility, we use two sources: demographic studies based upon genealogical records and our own analysis of census data.

The literature on Amish demography, which is typically based upon analyses of comprehensive genealogical records, indicates that fertility rates increased at approximately the same time as among the general U.S. population. Ericksen et al. (1979) compiled data from the four largest Amish settlements in the United States: Lancaster, Pennsylvania; Elkhart, Indiana; and Holmes and Geauga Counties, Ohio. Between the 1909-18 birth cohort of Amish women and the 1929-38 cohort, they document a decline in the proportion of childless women, a rise in age-specific marital fertility for 20-24 and 25-29 year olds, and a rise in cumulative marital fertility by about 0.6 children at age 35 (258-260). This corresponds fairly closely to our census-based estimates, which are presented below. Markle and Pasco (1977) relied on the Indiana Amish Directory from 1971 to calculate period fertility rates. Between 1935-39 and 1955-59, the average age at marriage for women in their sample fell from 22.8 to 20.8 years, and the average time between marriage and first birth declined. Between 1935-39 and 1960-64, they also document large increases in birthrates among women in their 20s (274, figure 1). ${ }^{21}$ Most recently, Greska (2002) compiled data from a 1993 directory for the Amish settlement in Geauga, Ohio, including 1,337 women. Consistent with the studies above, he finds a dip in age at first marriage and age at first birth for the 1928-37 birth cohorts of women, and he reports that the 1928-37 cohorts had a cumulative fertility rate that was 0.42 higher than the 1908-17 cohorts, and 0.49 higher than the 1918-27 cohorts (195-197).

We can corroborate this interpretation of Amish demographic history by examining completed fertility of Amish and non-Amish women from the same birth cohorts in the IPUMS. Specifically, using information on the primary language spoken at home (Pennsylvania Dutch) in the 1940, 1980, and 1990 IPUMS (the only census years with information on language spoken and children ever born), we attempt to document changes in completed fertility among the Amish. It is well established that the Old Order Amish speak Pennsylvania Dutch and that the vast majority of active, primary speakers of Pennsylvania Dutch are Old Order Amish (or from smaller groups of

\footnotetext{
${ }^{21}$ Markle and Pasco do not report the exact birthrate figures, but rather present a graph (1977: 274, figure 1). From their figure, we infer that the birthrate (divided by 1000) for women aged 20-24 increased from approximately 0.30 to 0.53 , and for women 25-29 it increased from about 0.38 to 0.48. In earlier work, Smith (1960) studied the Amish in rural southeastern Pennsylvania. He also reports that birth spacing was significantly shorter for Amish women who married in the 1940s and 1950s compared to earlier cohorts (104).
} 
conservative Old Order Mennonites). ${ }^{22}$ Because we do not observe religion in the Census, we call the sample of those who report Pennsylvania Dutch as their primary language the "likely Amish." To obtain the largest possible sample, we pool all of the available 1940, 1980 and 1990 IPUMS samples. The resulting sample of likely Amish consists of 1,915 women ages 35 to 85 at the time of observation who spoke Pennsylvania Dutch at home (1980 and 1990) or as their mother tongue (1940). For comparison groups, we create samples of ever-married women in the same birth cohorts who were residing on farms in Indiana, Ohio, and Pennsylvania (states with the largest Amish populations) and all U.S. women not residing on farms.

Figure 7 plots the mean number of children ever born by birth cohort (web appendix 2 presents summary statistics for this sample). In each year, U.S. native, nonfarm residents have the lowest completed fertility rate, followed by women on farms in Indiana, Ohio, and Pennsylvania. The "likely Amish" women had higher levels of completed fertility than the non-farm population, as one might expect in an agrarian population, but comparable levels to the farm populations of Indiana, Ohio, and Pennsylvania. The key result of this analysis is that the fertility trend of the "likely Amish" closely tracks those in the two comparison groups. In a reversal of a long period of fertility decline, each of the groups in figure 7-including the Amish-had large increases in completed fertility among the cohorts of women born after 1910. In the U.S. nonfarm sample and in the Indiana, Ohio and Pennsylvania farm sample, completed fertility increased by roughly 0.87 (s.e. 0.004 ) and 1.03 (s.e. 0.070) births per woman, respectively, from trough (1900-1909) to peak cohorts (1930-34). The "likely Amish” group experienced a statistically significant increase of 1.24 births (s.e. 0.24 ) over the same period, which is statistically indistinguishable from the farm population baby boom.

Given that we cannot observe religious affiliation in the census data and that non-Amish speakers of Pennsylvania Dutch may contaminate our sample, we examine the robustness of our

\footnotetext{
${ }^{22}$ In personal correspondence, Karen Johnson-Weiner, a linguist associated with the Elizabethtown College Amish Studies Program and a Professor of Anthropology at SUNY-Potsdam, confirmed that the overwhelming majority of Pennsylvania German speakers (how linguists often refer to Pennsylvania Dutch) are Old Order Amish or conservative "horse-and-buggy" groups of Old Order Mennonites. See also Moelleken (1988) and Huffines (1980) who discuss the persistence of Pennsylvania Dutch among the Amish and its decline among secular speakers. Elizabethtown College's Amish Studies program in the Young Center for Anabaptist and Pietest Studies provides helpful information in this regard. The Center's website notes that "Regardless of where they live, the Amish speak the Pennsylvania German dialect (popularly known as Pennsylvania Dutch), except in a few communities where they speak a Swiss Dialect." This is the primary language of the Amish. It also notes that "Although the Amish originally comprised only a small minority of the Pennsylvania German-speaking population [in the 1700s], they and the Old Order Mennonites are the last groups to use the language actively and pass it on to their children" (Kraybill et al. 2010).
} 
findings for the "likely Amish" using several approaches. Our first check entails restricting the sample to those who reported having no telephone in 1980 and 1990, which we plot in figure 7 for comparison. ${ }^{23}$ This restriction is likely to capture the most observant of the Older Order Amish and eliminate secular speakers of Pennsylvania Dutch. The no-phone likely Amish sample has a substantially higher fertility rate than the other groups, and it experienced a similar rise in fertility from trough to peak of 1.3 births, s.e. 0.50, p-value 0.073).

Our second check entails excluding everyone from the likely Amish sample that resided in Pennsylvania, which is where non-Amish speakers of Pennsylvania Dutch would most likely be concentrated. This sample restriction alters the results little. The 1910-to-peak increase is 0.83 births (s.e. 0.40, p-value 0.04).

Our third check is a back-of-envelope calculation to estimate the proportion of the "likely Amish" sample that would have to be misclassified to generate the observed increase in fertility if, in fact, the Amish did not have a baby boom. Let $\mathrm{F}_{\mathrm{A}}$ be Old Order Amish fertility, $\mathrm{F}_{\mathrm{N}}$ be fertility among those who are not Old Order Amish, and $\mathrm{F}^{*}$ be the completed fertility we observe for those who speak Pennsylvania Dutch at home in 1980 and 1990. Observed fertility of Pennsylvania-Dutch speakers can be written as a weighted average of the two groups, $a \mathrm{~F}_{\mathrm{A}}+(1-a) \mathrm{F}_{\mathrm{N}}=\mathrm{F}^{*}$, where $a$ is a scalar weight representing the proportion of Pennsylvania Dutch speakers who are Old Order Amish, $0 \leq a \leq 1$. The change in $\mathrm{F}^{*}$ from trough (1900-1909) to peak cohorts (1930-34), $\Delta \mathrm{F}^{*}$, can be written as $\Delta \mathrm{F}^{*}=(1-a) \Delta \mathrm{F}_{\mathrm{N}}$, under the null hypothesis that the Old Order Amish did not have a baby boom $\left(\Delta \mathrm{F}_{\mathrm{A}}=0\right)$ and that $a$ is time-invariant. How large would 1- $a$ (the proportion of non-Amish, Pennsylvania Dutch speakers) have to be in order for us to find a baby boom equal in size to $\Delta \mathrm{F}^{*}$ if there were no increase among the Amish $\left(\Delta \mathrm{F}_{\mathrm{A}}=0\right)$ ? Fertility among U.S. farm residents increased by 1.03 , which we use to proxy $\Delta \mathrm{F}_{\mathrm{N}}$. Fertility among those in our sample of Likely Old Order Amish (no phones), $\Delta \mathrm{F}^{*}$, increased by 1.3. Therefore, we estimate that our mis-measurement of the Amish would have to be $(1-a)=\Delta \mathrm{F}^{*} / \Delta \mathrm{F}_{\mathrm{N}} \cong 1.3 / 1.03=1.26$, which is impossible since 1-a must be less than 1 . Alternatively, taking $\Delta \mathrm{F}^{*}$ to be the increase among the nonPennsylvania-resident Pennsylvania Dutch speakers, the measurement error would have to be severe at 80 percent to generate the observed baby boom if the Amish did not have one. Not only is this an implausibly high misclassification rate, but it is also inconsistent with the demographic literature cited above, which shows evidence of a conspicuous increase in fertility in Amish genealogical records that are not subject to the same concerns about misclassification. In short, the evidence

\footnotetext{
${ }^{23}$ The Old Order Amish remain more conservative than some other Anabaptist groups who may also speak Pennsylvania Dutch. See Kraybill (1994) for discussion of splits within the Amish and differences across groups in appliance use in the 1990s in Holmes County, Ohio; see Umble (1994) for a discussion of phone use.
} 
strongly suggests that the Amish had a baby boom that roughly began at the same time, lasted at least as long, and matched the magnitude of the boom in the rest of the U.S. population.

\section{Implications for Theories of Fertility and the Baby Boom}

On its face, empirical evidence that fertility did not rise with changes in technology seems inconsistent with canonical price theory. How could a reduction in the price of childrearing (embodied in the improvement of household technology) not result in an increase in the number of children born?

To reconcile this paper's evidence with economic theory, consider a static framework where households maximize utility, $U(N, H, Z)$, defined over a composite, non-home-produced commodity, $Z$ (referred to as the composite good); the number of children, $N$; and a non-child, home-produced good, $H$. Some examples of the goods in $H$ might include listening to music (produced with a combination of time and a record player or radio); cleaning one's home or clothing (produced with time and a washing machine or other appliances); or making or ironing one’s clothes (produced with time and a sewing machine or iron). Alternatively, $H$ might be conceptualized as "child quality” as considered in Becker (1960), Becker and Lewis (1973), and Willis (1973), because child quality might include commodities like healthy meals, which may require fresh produce or meat to be refrigerated, or dance lessons, which could require automobile transportation to schools or studios. Let the price of the composite good, $p$, be normalized to 1 ; the relative shadow price of children be $p_{N}$; and relative shadow price of non-child household goods be $p_{H}$. Assume there is an exogenous shock, $A$, that reduces $p_{N}$ and potentially $p_{H}$.

In this framework, the demand for children is a function of the relative prices and income, $I$; that is, $N=N\left(p_{N}, p_{H}, I\right)$. Differentiating with respect to A and using the Slutsky equation, the impact of $A$ on the number of children can be summarized,

$$
\left.\frac{d N\left(p_{N}, p_{H}, I\right)}{d A}\right|_{\mathrm{I}}=\left[\frac{\partial N^{C}}{\partial p_{N}}-\frac{\partial N}{\partial I} N\left(p_{N}, p_{H}, I\right)\right] \frac{\partial p_{N}}{\partial A}+\left[\frac{\partial N^{C}}{\partial p_{H}}-\frac{\partial N}{\partial I} H\left(p_{N}, p_{H}, I\right)\right] \frac{\partial p_{H}}{\partial A} .
$$

where $\frac{\partial N^{C}}{\partial p_{N}}$ is the compensated own-price effect and should be nonpositive, $\frac{\partial N^{C}}{\partial p_{N}} \leq 0$, and $\frac{\partial N^{C}}{\partial p_{H}}$ is the compensated cross-price effect with a sign that depends upon the complementarity or substitutability of children and other home-produced commodities, $\frac{\partial N^{C}}{\partial p_{H}} \geq 0$. The income effect should be nonnegative $\frac{\partial N}{\partial I} \geq 0$, if children are a normal good. Here, the sign of the first bracketed term multiplied by $\frac{\partial p_{N}}{\partial A}$ in equation 4 is positive: both the substitution and income effects encourage the production of more children when the shadow price of children falls as $A$ rises. The sign of the second bracketed term is theoretically ambiguous. For instance, if $N$ and $H$ are gross substitutes 
(implying the cross-price effect is positive, $\left.\frac{\partial N^{C}}{\partial p_{H}}-\frac{\partial N}{\partial I} H\left(p_{N}, p_{H}, I\right)>0\right)$ and the price of the other good falls with $A, \frac{\partial p_{H}}{\partial A}<0$, then the sign would be positive.

This framework organizes several insights about price-based explanations for the baby boom. Consider, first, the case where $A$ represents an exogenous improvement in household technology, which would affect both the price of children and of other home-produced goods. In the generalized framework of equation 4, this implies that improvements in household technology have a theoretically ambiguous impact on children born. A crucial, simplifying assumption underlying the unambiguously positive relationship between household productivity and the number of children in the GSV model is that there is only one home-produced good. Assuming that households do not value other home produced goods, $H$, implies that the second bracketed term in equation 4 is zero, which implies that the number of children rises with the productivity of household technology, or $\frac{d N}{d A}>0$.

The addition of $H$ to the model, however, implies that the fertility response depends upon the relative magnitudes of the first and second bracketed terms in equation 4, as well as the magnitude of the change in the shadow prices of $N$ and $H$. A baby boom or a baby bust (or neither) may result in response to an increase in $A$. And, even if the number of children does increase on net with advances in household technology, reductions in the price of other home-produced goods or, perhaps, substitution toward child quality (away from quantity) would temper the magnitude of this positive fertility response. ${ }^{24}$ Thus, it is far from a foregone conclusion that a baby boom should result from even a large improvement in household technology.

It is precisely this theoretical ambiguity that motivates our empirical analysis. Through the lens of this framework, our empirical results do not support the household-technology explanation of the baby boom, but they are consistent with other home-produced commodities (with prices also impacted by advances in household technology) being gross substitutes with children during the 1940 to 1960 period. $^{25}$

\footnotetext{
${ }^{24}$ Mokyr (2000) describes an historical shift in demand for cleanliness driven by changes in knowledge about the sources of disease that is consistent with naming $H$ "child quality."

${ }^{25}$ Analyzing the indirect impact of household technology on the U.S. population and the Amish is also possible in this framework. One possible indirect effect of technology on the Amish is through market prices for Amish goods sold to the market. A reduction in the sales price of Amish goods would reduce Amish incomes and, therefore, reduce consumption of both children and other goods. On the other hand, it would reduce the opportunity cost of childrearing and therefore have an ambiguous impact on fertility. The net impact of these effects could increase Amish fertility, but it would be remarkable if the combination of these indirect effects increased Amish fertility by roughly as much as the direct effects of household technology in the rest of the population. Moreover, to argue that
} 
Consider, next, two cases in which exogenous shocks may have affected the cost of children through channels other than household technology: a fall in young women's wages in the wake of World War II (Doepke et al. 2008) and improvements in medical technology specific to child-birth and rearing (Albanesi and Olivetti 2009). Like household-production technology shocks, a fall in young women's relative wages following World War II would affect both the price of children and the price of other home-produced goods. If children are more intensive in young women's time than other home-produced goods, then the reduction in young women's potential wages would induce households to shift towards more home goods and children in particular. Offsetting this effect would be the reduction in a household's permanent income (through a drop in women's potential, permanent earnings), which would tend to reduce the number of children. The fertility response, therefore, depends upon these price and income elasticities as well as the magnitudes of the shifts in relative prices.

Improvement in medical technology specific to child-birth and rearing may also have price and income effects. If, for instance, these improvements affected only the shadow price of having or rearing children (the introduction of infant formula, for instance) and $\frac{\partial p_{H}}{\partial A}=0$, then the fertility effect would be unambiguously positive. If, on the other hand, the new technologies affected the shadow price of other home production or permanent income (through changes in maternal morbidity, for instance), then the fertility response would, again, be theoretically ambiguous.

Because economic theory does not provide definitive answers about the sign or magnitude of the effects of changes in young women's wages or improvements in medical technology, detailed empirical investigations of each of these hypotheses will be important contributions to future research on the baby boom. Our specific analyses of the diffusion of household technology in sections I and II do not bear directly on these alternative explanations, but close historical and econometric investigations will prove helpful in assessing them. For example, there was considerable variation across places in the intensity of wartime production and women's wartime labor force participation (Dresser 1994; Acemoglu, Autor, and Lyle 2004), which might shed light on the strength of war-induced, labor-supply shocks that affected young women's wages and, more generally, could help test explanations that emphasize World War II's role in the baby boom. Likewise, variation in levels and changes in maternal and infant health (Thomasson and Treber 2008; Jayachandran, Lleras-Muney, and Smith 2010) might shed light on the medical technology 
hypothesis. In addition, developing case studies of groups or places that were relatively "untreated" in a dimension that is specific to the hypothesis at hand may provide valuable evidence, though such exceptions are difficult to find. ${ }^{26}$

Finally, our evidence does not bear directly on Easterlin's long-standing hypothesis (1961, 1980), and the data's lack of support for the mechanism proposed in GSV is not an implicit endorsement of the Easterlin explanation. Unlike the comparatively new hypotheses of GSV (2005), Doepke et al. (2008), and Albanesi and Olivetti (2009), a large empirical literature explores Easterlin's hypothesized changes in “material aspirations”. Because these are difficult to observe directly or identify econometrically, ${ }^{27}$ and detailed family income data are sparse in the first half of the twentieth century, tests of the Easterlin hypothesis have yielded mixed results (Pampel and Peters 1995, Macunovich 1998), and the extent to which intergenerational shifts in preferences can explain the U.S. baby boom remains unclear.

\section{Conclusions}

The mid-twentieth-century rise in fertility is a compelling puzzle not only because it was a dramatic departure from the previous 100 years of American demographic history, but also because it unfolded against a background of rising income, urbanization, educational attainment, infant health, and women's labor force participation-many of the factors that economists and demographers typically associate with declining fertility. Women who reached their childbearing years in the 1940s and 1950s (women born between 1920 and 1935) got married younger, bore their first child sooner, and had more children over their lifetimes than women born earlier and later in the century. More than 50 years since the baby boom's peak, there is no scholarly consensus about its causes.

Our goal in this paper is to weigh the empirical evidence supporting the importance of changes in household-productivity in causing the baby boom. This explanation is clearly articulated and explicitly linked to electrification and modern household appliances, which allows us to test its empirical content. Three alternative methodologies provide no support for this explanation of the baby boom: Timeseries patterns in the diffusion of household technology and electrification provide no evidence of acceleration in household productivity over the period of the baby boom. Linear

\footnotetext{
${ }^{26}$ The Amish, for example, were connected to the rest of economy through their production and sale of agricultural goods; they did not refuse modern medical care; and many served in the Civilian Public Service during World War II (Hershberger 1951). They did not, however, embrace modern household appliances. These characteristics make them a useful comparison group in the context of our study, but perhaps less useful in testing other explanations of the baby boom.

${ }^{27}$ Malmendier and Nagel (2009) find evidence consistent with the claim that the macroeconomic environment early in one's life can have a persistent influence on attitudes toward financial risk.
} 
regressions using county-level data and alternative measures of the "state of household technology," in specifications with and without covariates in each year from 1940 to 1960 and in first-differenced regressions, show no evidence of a positive correlation between measures of household productivity and fertility. Finally, a large, coincident fertility increase among the Amish further challenges the hypothesis that modern household production technology caused the U.S. baby boom. Overall, the empirical evidence is consistent with a model in which other home-produced commodities are gross substitutes for the quantity of children.

Although this paper concentrates on a single specific hypothesis, insights emerge that can inform broader research on demographic history and the baby boom. First, whatever factors explain the American baby boom must account for its occurrence in urban and rural areas, among different educational and racial groups, and in all regions. It was a remarkably pervasive event, and scholars should endeavor to explain the near simultaneity of baby booms in places and populations that varied widely in their social and economic circumstances (Jones and Tertilt 2008). At the same time, we find that although the baby boom was widespread, the boom was not evenly spread, and the variation in changes in fertility invites analyses based on detailed cross-place and cross-household data. Both Easterlin's pioneering work and Greenwood, Seshadri, and Vandenbroucke's argument are based on national-level time-series patterns in the United States, but more disaggregated views may prove extremely valuable, and indeed necessary, for discerning among the many potential causes. 


\section{References}

Albanesi, Stefania and Claudia Olivetti. 2009. “Gender Roles and Medical Progress.” NBER Working Paper 14873. Cambridge, MA: NBER.

Acemoglu, Daron, David H. Autor, and David Lyle. 2004. "Women, War, and Wages: The Effect of Female Labor Supply on the Wage Structure at Midcentury.” Journal of Political Economy 112, 3: 497-551.

Barro, Robert J. and Gary S. Becker. 1988. "A Reformulation of the Economic Theory of Fertility.” Quarterly Journal of Economics 103, 1: 1-25.

Becker, Gary S. 1960. “An Economic Analysis of Fertility.” In Demographic and Economic Change in Developed Countries, ed. Gary Becker, 208-230. Princeton, N.J.: Princeton University Press.

Becker, Gary S. 1965. “A Theory of the Allocation of Time,” Economic Journal 75 (299): 493-517.

Becker, Gary S. and H. Gregg Lewis. 1973. “On the Interaction between the Quantity and Quality of Children.” Journal of Political Economy 81, 2: S279-S288.

Beecher, Catharine. 1841. A Treatise on Domestic Economy. Boston, MA.

Bowden, Sue and Avner Offer. 1994. "Household Appliances and the Use of Time: The United States and Britain since the 1920s.” Economic History Review 47, 4: 725-748.

Bresnahan, Timothy F. and Robert J. Gordon. 1997. "Introduction.” In The Economics of New Goods, eds. Timothy F. Bresnahan and Robert J. Gordon, 1-26. Chicago, IL: University of Chicago Press.

Brunsman, Howard G. and Dave Lowery. 1943. "Facts from the 1940 Census of Housing.” Journal of Land \& Public Utility Economics 19, 1: 89-93.

Carter, Susan B. et al. 2006. Historical Statistics of the United States: Earliest Times to the Present. New York: Cambridge University Press.

Cowan, Ruth Schwartz. 1983. More Work for Mother: The Ironies of Household Technology from the Open Hearth to the Microwave. New York: Basic Books.

Cox, W. Michael and Richard Alm. 1997. "Time Well Spent: The Declining Real Cost of Living in America.” 1997 Annual Report. Dallas, TX: Federal Reserve Bank of Dallas.

David, Paul A. and Peter Solar. 1977. "A Bicentennary Contribution to the History of the Cost of Living in America.” Research in Economic History 2: 1-80.

Doepke, Matthias, Moshe Hazan, and Yishay Maoz. 2008. "The Baby Boom and World War II: A Macroeconomic Analysis. CEPR Discussion Paper 6628.

Dresser, Laura. 1994. Changing Labor Market Opportunities of White and African-American Women in the 1940s and the 1980s. Ph.D. Dissertation, University of Michican.

Easterlin, Richard A. 1961. "The American Baby Boom in Historical Perspective.” American Economic Review 51, 5: 869-911.

Easterlin, Richard A. 1980. Birth and Fortune: The Impact of Numbers on Personal Welfare. New York: Basic Books.

Edison Electric Institute. Annual issues 1933-1961.The Electric Light and Power Industry, Statistical Bulletin. New York.

Ericksen, Julia A., Eugene P. Ericksen, John A. Hostetler, and Gertrude E. Huntington.1979. “Fertility Patterns and Trends Among the Old Order Amish.” Population Studies 33, 2: 255276. 
Field, Alexander J. 2003. “The Most Technologically Progressive Decade of the Century.” American Economic Review 93, 4: 1399-1413.

Frederick, Christine. 1912. “The New Housekeeping.” Ladies’ Home Journal: Sept.-Dec.

Giedion, Siegfried. 1948. Mechanization Takes Command: A Contribution to Anonymous History. New York: Oxford University Press.

Godley, Andrew. 2001. “The Global Diffusion of the Sewing Machine, 1850-1914.” Research in Economic History 20: 1-45.

Gordon, Robert J. 2000. “Interpreting the 'One Big Wave’ in U.S. Long-term Productivity Growth.” In Productivity, Technology, and Economic Growth, ed. Bart van Ark, Simon Kuipers, and Gerard Kuper, 19-65. Boston, MA: Kluwer Publishers.

Gordon, Robert J. 1990. The Measurement of Durable Goods Prices. Chicago, IL: University of Chicago Press.

Greenwood, Jeremy, Ananth Seshadri, and Guillaume Vandenbroucke. 2005. "The Baby Boom and Baby Bust.” American Economic Review 95, 1: 183-207.

Greska, L.P. 2002. "Population Growth and Fertility Patterns in an Old Order Amish Settlement.” Annals of Human Biology 29, 2: 192-201.

Griliches, Zvi (ed.). 1971. Price Indexes and Quality Change: Studies in New Methods of Measurement. Cambridge, MA: Harvard University Press.

Haines, Michael R. 2006. "Vital Statistics.” In Historical Statistics of the United States: Earliest Times to the Present, ed. Susan Carter et al., 1-381 - 1-390. New York: Cambridge University Press.

Haines, Michael R., and the Inter-university Consortium for Political and Social Research. 2004. Historical, Demographic, Economic, and Social Data: The United States, 1790-2000 [Computer file]. ICPSR02896-v2. Hamilton, NY: Colgate University/Ann Arbor: MI: Interuniversity Consortium for Political and Social Research [producers]. Ann Arbor, MI: Interuniversity Consortium for Political and Social Research [distributor].

Harris, Howell J. 2008. "Inventing the U.S. Stove Industry, c.1815-1875: Making and Selling the First Universal Consumer Durable.” Business History Review 82, 4: 701-733.

Hershberger, Guy Franklin. 1951. The Mennonite Church in the Second World War. Scottdale, Pa.: Mennonite Publishing House.

Hostetler, John A. 1963. Amish Society. Baltimore, MD: Johns Hopkins University Press.

Huffines, Marion Lois. 1980. "English in Contact with Pennsylvania German.” The German Quarterly 53, 3: 352-366.

Jayachandran, Seema, Adriana Lleras-Muney, and Kimberly V. Smith. 2010. "Modern Medicine and the Twentieth Century Decline in Mortality: Evidence on the Impact of Sulfa Drugs." American Economic Journal: Applied Economics, 2(2): 118-46.

Jones, Larry E. and Michele Tertilt. (2008). ”An Economic History of Fertility in the U.S.: 1826-1960," In Frontiers of Family Economics, vol. 1. ed. Peter Rupert, 165-225. Bingley, United Kingdom: Emerald Press.

Kendrick, John W. 1961. Productivity Trends in the United States. Princeton, NJ: Princeton University Press.

Kraybill, Donald B. 1994. "Plotting Social Change across Four Affiliations.” In The Amish Struggle with Modernity, ed. Donald B. Kraybill and Marc A. Olshan, 53-74. Hanover, NH: University Press of New England.

Kraybill, Donald B., Steven M. Nolt, and Karen Johnson-Weiner. 2010. “Amish Studies: Frequently Asked Questions.” Elizabethtown, PA: Young Center for Anabaptist and Pietist Studies at 
Elizabethtown College. http://www2.etown.edu/amishstudies/FAQ.asp, accessed June 10, 2010.

Lebergott, Stanley. 1976. The American Economy: Income, Wealth, and Want. Princeton, NJ: Princeton University Press.

Lebergott, Stanley. 1993. Pursuing Happiness: American Consumers in the Twentieth Century. Princeton, NJ: Princeton University Press.

Macunovich, Diane J. 1998. "Fertility and the Easterlin Hypothesis.” Journal of Population Economics 11: 53-111.

Malmendier, Ulrike and Stefan Nagel. 2009. “Depression Babies: Do Macroeconomic Experiences Affect Risk-Taking?” NBER Working Paper 14813. Cambridge, MA: NBER.

Margo, Robert A. 2006. “Labor: Wages and Inequality.” In Historical Statistics of the United States: Earliest Times to the Present, ed. Susan Carter et al., 2-40 - 2-46. New York: Cambridge University Press.

Markle, Gerald E. and Sharon Pasco. 1977. "Family Limitation Among the Old Order Amish.” Population Studies 31, 2: 267-280.

Moelleken, Wolfgang Wilfried. 1988. “A New Linguistic Atlas of Pennsylvania German.” Monatshefte 80, 1: 105-114.

Mokyr, Joel. 2000. “Why 'More Work for Mother?’ Knowledge and Household Behavior, 18701945.” Journal of Economic History 60, 1: 1-41.

Nolt, Steven M. 1992. A History of the Amish. Intercourse, PA: Good Books.

Nordhaus, William D. 1997. "Do Real-Output and Real-Wage Measures Capture Reality? The History of Lighting Suggests Not.” In The Economics of New Goods, eds. Timothy F. Bresnahan and Robert J. Gordon, 29-66. Chicago, IL: University of Chicago Press.

Raff, Daniel M.G. and Manuel Trajtenberg. 1997. "Quality-Adjusted Prices for the American Automobile Industry: 1906-1940.” In The Economics of New Goods, eds. Timothy F. Bresnahan and Robert J. Gordon, 71-107. Chicago, IL: University of Chicago Press.

Rees, Albert. 1961. Real Wages in Manufacturing, 1890-1914. National Bureau of Economic Research. Princeton, NJ: Princeton University Press.

Rogers, Carolyn C. and Martin O’Connell. 1984. "Childspacing among Birth Cohorts of American Women: 1905 to 1959.” Department of Commerce, Bureau of the Census, Current Population Reports, Series P-20, No. 385. Washington DC: U.S. GPO.

Ruggles, Steven, Matthew Sobek, Trent Alexander, Catherine A. Fitch, Ronald Goeken, Patricia Kelly Hall, Miriam King, and Chad Ronnander. 2006 and 2008. Integrated Public Use Microdata Series [Machine-readable database]. Minneapolis, MN: Minnesota Population Center [producer and distributor].

Ryder, Norman B. 1980. “Components of Temporal Variations in American Fertility.” In Demographic Patterns in Developed Societies, ed. R.W. Hiorns. London: Taylor and Francis.

Sanderson, Warren C. 1976. “On Two Schools of the Economics of Fertility,” Population and Development Review 2 (3-4): 469-477.

Smith, Elmer L. 1960. Studies in Amish Demography. Harrisonburg, Virginia: Research Council, Eastern Mennonite College.

Snowden, Kenneth A. 2006. “Construction, Housing, and Mortgages.” In Historical Statistics of the United States: Millennial Edition, eds. Susan Carter et al. New York: Cambridge University Press. 
Strasser, Susan. 2000 [originally 1982]. Never Done: A History of American Housework. New York: Henry Holt and Company.

Thomasson, Melissa A. and Jaret Treber. 2008. "From Home to Hospital: The Evolution of Childbirth in the United States, 1928-1940.” Explorations in Economic History 45, 1: 76-99.

Umble, Diane Zimmerman. 1994. "Amish on the Line: The Telephone Debates.” The Amish Struggle with Modernity, eds. Donald B. Kraybill and Marc A. Olshan, 97-111. Hanover, NH: University Press of New England.

U.S. Department of Commerce. 1975. Historical Statistics of the United States: Colonial Times to 1970. Washington DC: GPO.

U.S. Department of Commerce, Bureau of the Census. 1943. Sixteenth Census of the United States: 1940. Housing, Volume II: General Characteristics. Washington, DC: Government Printing Office.

U.S. Department of Commerce, Bureau of the Census. 1953. Census of Housing: 1950. Volume I: General Characteristics. Washington, DC: Government Printing Office.

U.S. Department of Commerce, Bureau of the Census. 1963. Census of Housing, 1960. Volume I: States and Small Areas. Washington, DC: Government Printing Office.

Willis, Robert J. 1973. “A New Approach to the Economic Theory of Fertility Behavior.” Journal of Political Economy 81, 2: S14-S64. 
Table 1. Summary Statistics, U.S. County-Level Data

\begin{tabular}{|c|c|c|c|}
\hline & 1940 & 1950 & 1960 \\
\hline $\begin{array}{l}\text { Infants per } 1,000 \text { women of age } 15 \\
\text { to } 44\end{array}$ & $\begin{array}{l}79.9 \\
(17.4)\end{array}$ & $\begin{array}{l}105.6 \\
(17.5)\end{array}$ & $\begin{array}{l}120.1 \\
(20.2)\end{array}$ \\
\hline $\begin{array}{l}\text { Proportion of housing units with } \\
\text { electric lights }\end{array}$ & $\begin{array}{l}55.0 \\
(24.7)\end{array}$ & $\begin{array}{l}85.0 \\
(13.0)\end{array}$ & --- \\
\hline $\begin{array}{l}\text { Proportion of housing units with a } \\
\text { mechanical refrigerator }\end{array}$ & $\begin{array}{l}27.1 \\
(14.8)\end{array}$ & $\begin{array}{l}67.7 \\
(16.2)\end{array}$ & --- \\
\hline $\begin{array}{l}\text { Proportion of housing units with a } \\
\text { modern stove (using gas or } \\
\text { electricity as fuel) }\end{array}$ & $\begin{array}{l}23.0 \\
(22.5)\end{array}$ & $\begin{array}{l}54.6 \\
(24.0)\end{array}$ & $\begin{array}{l}87.5 \\
(13.3)\end{array}$ \\
\hline $\begin{array}{l}\text { Proportion of housing units with a } \\
\text { power-driven washing machine }\end{array}$ & --- & --- & $\begin{array}{l}78.3 \\
(12.4)\end{array}$ \\
\hline
\end{tabular}

Notes: The table reports unweighted averages across U.S. counties (excluding Hawaii and Alaska). Standard deviations are in parentheses. Counties that are omitted from table 2's regressions are also excluded in this table, but this has little effect on the reported figures.

Sources: Infants per woman, proportion of homes with lights (in 1940), refrigerators, and washing machines are from Haines (2004). We compiled data on electric lighting in 1950 and stoves in all years from the published volumes of the Census of Housing (U.S. Department of Commerce 1943, 1953, 1963). See data appendix for more information about the dataset. 
Table 2. Cross-Sectional Regressions of Fertility on Appliances in U.S. Counties, 1940-1960

\begin{tabular}{|c|c|c|c|}
\hline & \multicolumn{3}{|c|}{$\begin{array}{l}\text { Dependent Variable: } \\
\text { General Fertility Rate }\end{array}$} \\
\hline & (1) & (2) & (3) \\
\hline \multicolumn{4}{|l|}{ Panel A: 1940} \\
\hline \multirow[t]{2}{*}{ Percent with refrigerator } & -0.689 & -0.665 & 0.017 \\
\hline & {$[0.056]$} & [0.067] & [0.050] \\
\hline Observations & 3034 & 3034 & 3034 \\
\hline R-squared & 0.34 & 0.50 & 0.63 \\
\hline \multirow[t]{2}{*}{ Percent with modern stove } & -0.428 & -0.410 & 0.029 \\
\hline & [0.034] & [0.038] & [0.034] \\
\hline Observations & 3034 & 3034 & 3034 \\
\hline R-squared & 0.31 & 0.48 & 0.63 \\
\hline \multicolumn{4}{|l|}{ Panel B: 1950} \\
\hline \multirow[t]{2}{*}{ Percent with refrigerator } & -0.402 & -0.483 & -0.401 \\
\hline & [0.056] & [0.057] & [0.104] \\
\hline Observations & 3031 & 3031 & 3031 \\
\hline R-squared & 0.14 & 0.39 & 0.48 \\
\hline \multirow[t]{2}{*}{ Percent with modern stove } & -0.193 & -0.246 & 0.004 \\
\hline & {$[0.036]$} & [0.033] & [0.049] \\
\hline Observations & 3031 & 3031 & 3031 \\
\hline R-squared & 0.07 & 0.35 & 0.47 \\
\hline \multicolumn{4}{|l|}{ Panel C: 1960} \\
\hline \multirow[t]{2}{*}{ Percent with washing machine } & -0.132 & -0.284 & 0.068 \\
\hline & {$[0.141]$} & {$[0.167]$} & [0.069] \\
\hline Observations & 3022 & 3022 & 3022 \\
\hline R-squared & 0.01 & 0.29 & 0.44 \\
\hline \multirow[t]{2}{*}{ Percent with modern stove } & -0.230 & -0.433 & -0.309 \\
\hline & {$[0.105]$} & [0.081] & [0.113] \\
\hline Observations & 3022 & 3022 & 3022 \\
\hline R-squared & 0.02 & 0.32 & 0.45 \\
\hline State fixed effects & No & Yes & Yes \\
\hline Economic and demographic controls & No & No & Yes \\
\hline
\end{tabular}

Notes: Each point estimate is from a separate regression corresponding to equation 1 . The dependent variable is the number of infants (under 1 year) per thousand women ages 15 to 44 . A "modern stove" is defined to use electricity or gas (not wood, coal, or kerosene). The unit of observation is a county. Heteroskedasticity-robust standard errors have been corrected for correlation at the state level and are reported in brackets. The covariates in column 3 include the urban proportion of the county's population, log population density, nonwhite proportion of the county's population, proportion of employment in agriculture and manufacturing (separately), median years of schooling for those over age 24, log of median property value, and the proportion of women in the labor force. The 1950 and 1960 specifications also control for log median family income (this variable is unavailable in 1940). The urban variable generally measures the proportion of the population residing in incorporated places with more than 2,500 
residents. The density measure is the log of residents per square mile. Nonwhite includes black and "other" racial categories. The proportion of workers employed in agricultural and manufacturing industries are expressed relative to total employment. The percent of women in the labor force is the ratio of all women in the labor force divided by the number of women over age 14. The median schooling variable in the 1940 table is for women, whereas in 1950 and 1960 it is for both men and women. Observations with missing values for any economic or demographic control variable are dropped to maintain a consistent sample across specifications. The inclusion of all counties-rather than just those with information for all covariates in each panel— yields similar results.

Sources: Data for refrigerators, washing machines, and covariates are from Haines (2004). Data on the type of cooking fuel, which are used to define "modern stoves," were entered from the published Census of Housing volumes (U.S. Department of Commerce 1943, 1953, 1963). 
Table 3. Differenced Regressions of Fertility on Appliances in U.S. Counties, 1940-1960

\begin{tabular}{lccc}
\hline & \multicolumn{3}{c}{ Dependent Variable: } \\
& $(1)$ & $(2)$ & $(3)$ \\
\hline & & & \\
Panel A: Refrigerators 1940-50 & & & \\
$\Delta$ Percent with refrigerator & -0.007 & -0.214 & -0.101 \\
& {$[0.099]$} & {$[0.089]$} & {$[0.094]$} \\
Observations & 3023 & 3023 & 3023 \\
R-squared & 0.00 & 0.20 & 0.28 \\
\hline & & & \\
Panel B: Modern stoves, 1940-60 & & & \\
$\Delta$ Percent with modern stove & -0.231 & -0.298 & -0.088 \\
& {$[0.052]$} & {$[0.047]$} & {$[0.049]$} \\
Observations & 2990 & 2990 & 2990 \\
R-squared & 0.04 & 0.29 & 0.42 \\
\hline & & & \\
Panel C: Modern stoves, 1950-60 & & & -0.044 \\
$\Delta$ Percent with modern stove & -0.201 & -0.185 & {$[0.053]$} \\
& {$[0.035]$} & {$[0.043]$} & 2990 \\
Observations & 2990 & 2990 & 0.24 \\
R-squared & 0.04 & 0.16 & Yes \\
\hline State fixed effects & No & Yes & Yes \\
Economic and demographic controls & No & No & \\
\hline
\end{tabular}

Notes: Each point estimate is from a separate regression corresponding to equation 2 . The dependent variable is the change in the number of infants (under 1 year) per thousand women ages 15 to 44 between two census years at the county-level. Heteroskedasticity-robust standard errors have been corrected for correlation at the state level and are reported in brackets. The covariates in column 3 include the change in urban proportion of the county's population, the change in log population density, the change in nonwhite proportion of the county's population, the change in proportion of employment in agriculture and manufacturing (separately), the change in median years of schooling for those over age 24, the change in log of median property value, and the change in the proportion of women in the labor force. Urban, density, nonwhite, employment and labor force variables are defined as in table 2's notes. In this table, for better comparability with the variables available in 1950 and 1960 (which include both men and women), the schooling variable in 1940 is the average of the median schooling values for men and women. When necessary, observations with missing values are dropped to maintain a consistent sample across specifications. The inclusion of all counties - rather than just those with information for all covariates in each panel-yields similar results.

Sources: Data for refrigerators, washing machines, and covariates are from Haines (2004). Data on the type of cooking fuel were entered from the published census volumes in each year as described in the data appendix. 
Table 4. Regressions of Period Fertility on Electrical Service, 1940-1950

\begin{tabular}{lccc}
\hline & \multicolumn{3}{c}{ Dependent Variable: } \\
& $(1)$ & $(2)$ & $(3)$ \\
\hline & & & \\
Panel A: Fertility cross section, 1940 & & & -0.171 \\
Percent with electric lights & -0.410 & -0.515 & {$[0.053]$} \\
& {$[0.034]$} & {$[0.034]$} & 3034 \\
Observations & 3034 & 3034 & 0.64 \\
R-squared & 0.34 & 0.55 & \\
\hline & & & -0.375 \\
Panel B: Fertility cross section, 1950 & & & {$[0.083]$} \\
Percent with electric lights & -0.506 & -0.553 & 3031 \\
& {$[0.072]$} & {$[0.047]$} & 0.48 \\
Observations & 3031 & 3031 & \\
R-squared & 0.14 & 0.40 & -0.182 \\
& & & {$[0.054]$} \\
Panel C: Fertility change, 1940-1950 & & & 3023 \\
$\Delta$ Percent with electric lights & -0.275 & -0.327 & 0.29 \\
& {$[0.044]$} & {$[0.042]$} & \\
Observations & 3023 & 3023 & Yes \\
R-squared & 0.08 & 0.24 & Yes \\
& & & \\
\hline State fixed effects & No & Yes & No \\
Economic and demographic controls & No & & \\
\hline
\end{tabular}

Notes and sources: See table 2. We compiled the data for electric lights in 1950 from the published volumes of the Census of Housing (U.S. Department of Commerce 1953); the 1940 electric light data are from Haines (2004). 
Table 5. Regressions of Children-Ever-Born on Exposure to Electrical Service

\begin{tabular}{lllll}
\hline & \multicolumn{4}{l}{ Dependent Variable: } \\
& \multicolumn{1}{l}{ Children Ever Born } & \\
\hline & $(1)$ & $(2)$ & $(3)$ & $(4)$ \\
Exposure to electricity x 100 & -0.008 & -0.008 & -0.008 & -0.008 \\
& {$[0.002]$} & {$[0.002]$} & {$[0.002]$} & {$[0.002]$} \\
State of birth f.e. & No & Yes & Yes & Yes \\
Year of birth f.e. & No & Yes & Yes & Yes \\
Race and education & No & No & Yes & Yes \\
Husband's education & No & No & No & Yes \\
Observations & 1034 & 1034 & 1034 & 1034 \\
R-squared & 0.877 & 0.880 & 0.880 & 0.881 \\
\hline
\end{tabular}

Notes: The dependent variable is the mean self-reported children-ever-born to ever married women. Observations are birth state-birth year cells. Heteroskedasticity-robust standard errors have been corrected for correlation by birth state and are reported in brackets. The numerator for "mean exposure to electricity" in a given state-year cell is constructed from Edison Electrical Institute (EEI) Statistical Bulletin which contains annual state-level information on the number of residential electrical customers from 1925 to 1960. In the EEI data, Maryland and Washington DC customers are always counted together. North Carolina and South Carolina customers are often counted together. For consistency we have used these larger units of aggregation for all years. To calculate the denominator, we use the housing unit count from the census (interpolated between dates). "Exposure to electricity" is calculated as the mean of this proportion over the peak child-bearing years (15 to 29) for each year-of-birth and birth state cohort (and multiplied by 100). The sample includes women born from 1910 to 1931 (22 cohorts) and 47 geographic units for 1034 observations.

Sources: Edison Electric Institute Statistical Bulletin (various years) and 1960-1990 IPUMS (Ruggles et al. 2006). 
Figure 1. U.S. General Fertility Rate and Children Ever Born from 1895 to 1985

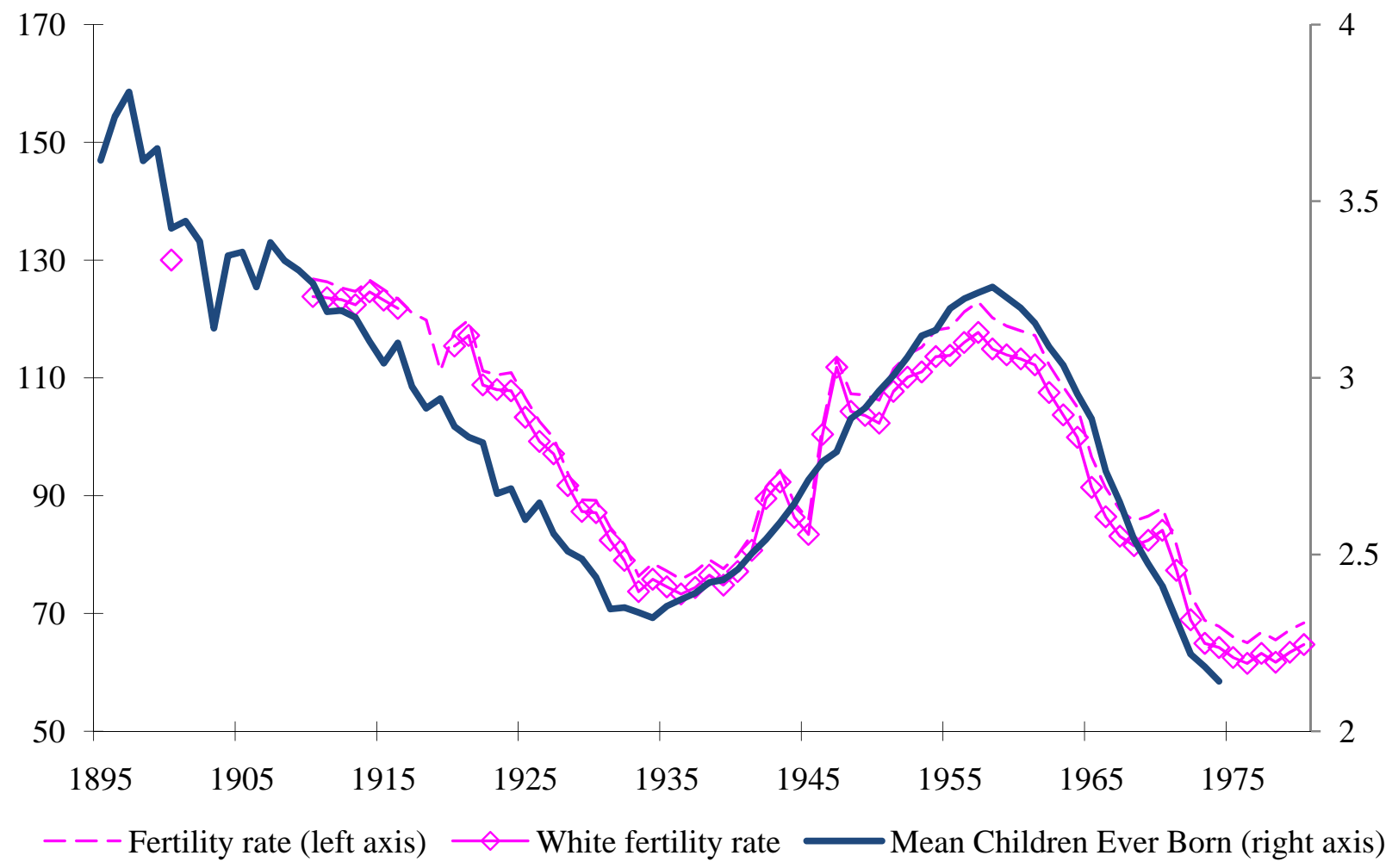

Notes: The outcome variables are the period fertility rate and the mean self-reported number of children by birth cohort. Birth cohorts are indexed to year of birth and increased by 25 years. For instance, the birth cohort of 1870 corresponds to the year 1895 on the graph's horizontal axis. Computations using the IPUMS use population weights.

Sources: Annual fertility rates are calculated using Historical Statistics, http://www.cdc.gov/nchs/data/statab/t001x01.pdf. The mean number of children ever born per woman is calculated using a sample of ever-married women ages 41 to 70 in the 1950, 1960, 1970, 1980 and 1990 IPUMS (Ruggles et al. 2008). 
Figure 2. Proportion of Households with Modern Household Technology, 1890-1970

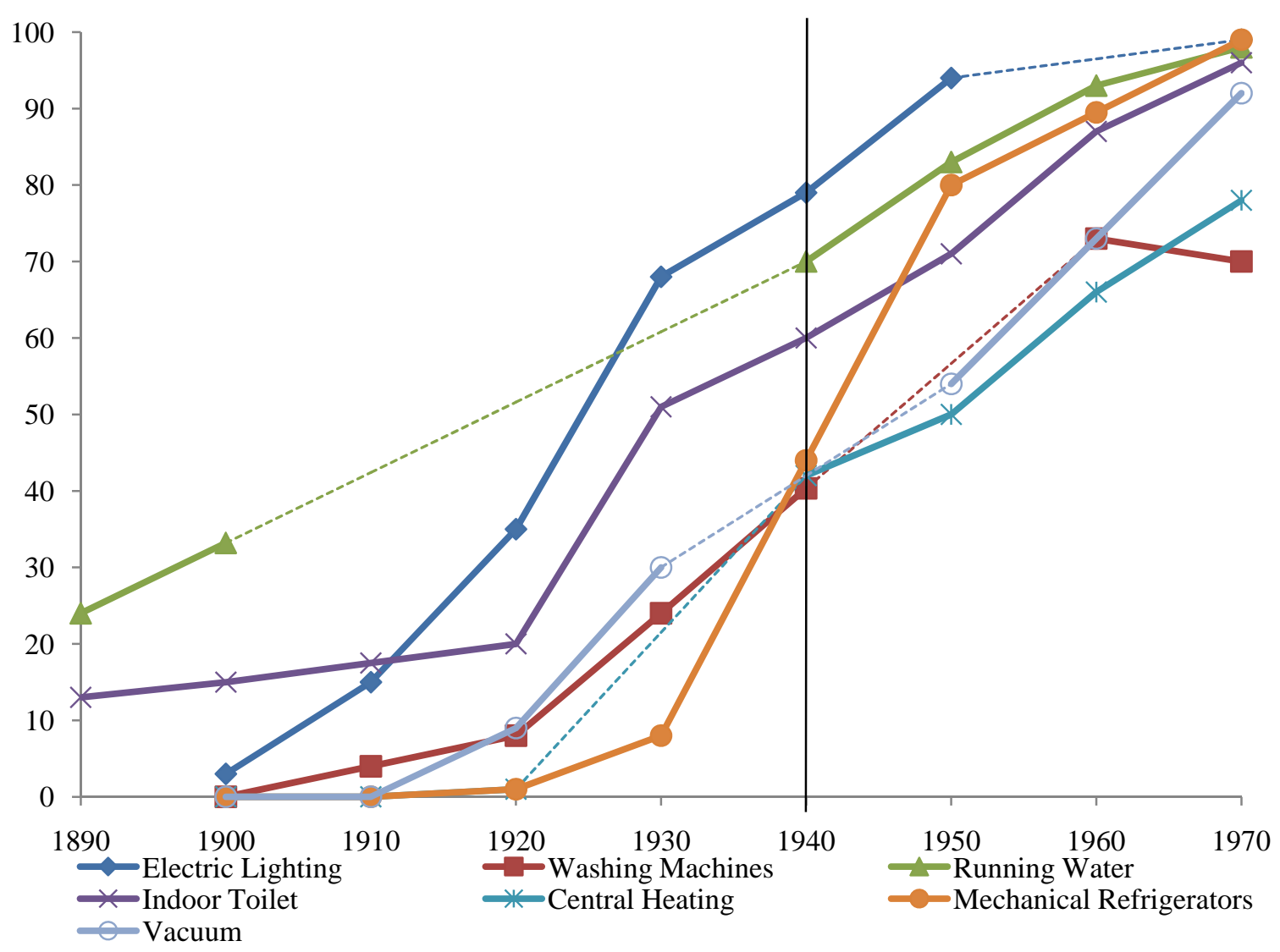

Note: Dashed lines indicate linear interpolation between data points.

Source: Lebergott (1976: 260-288). 
Figure 3. Real Wage Index $(1860=100)$

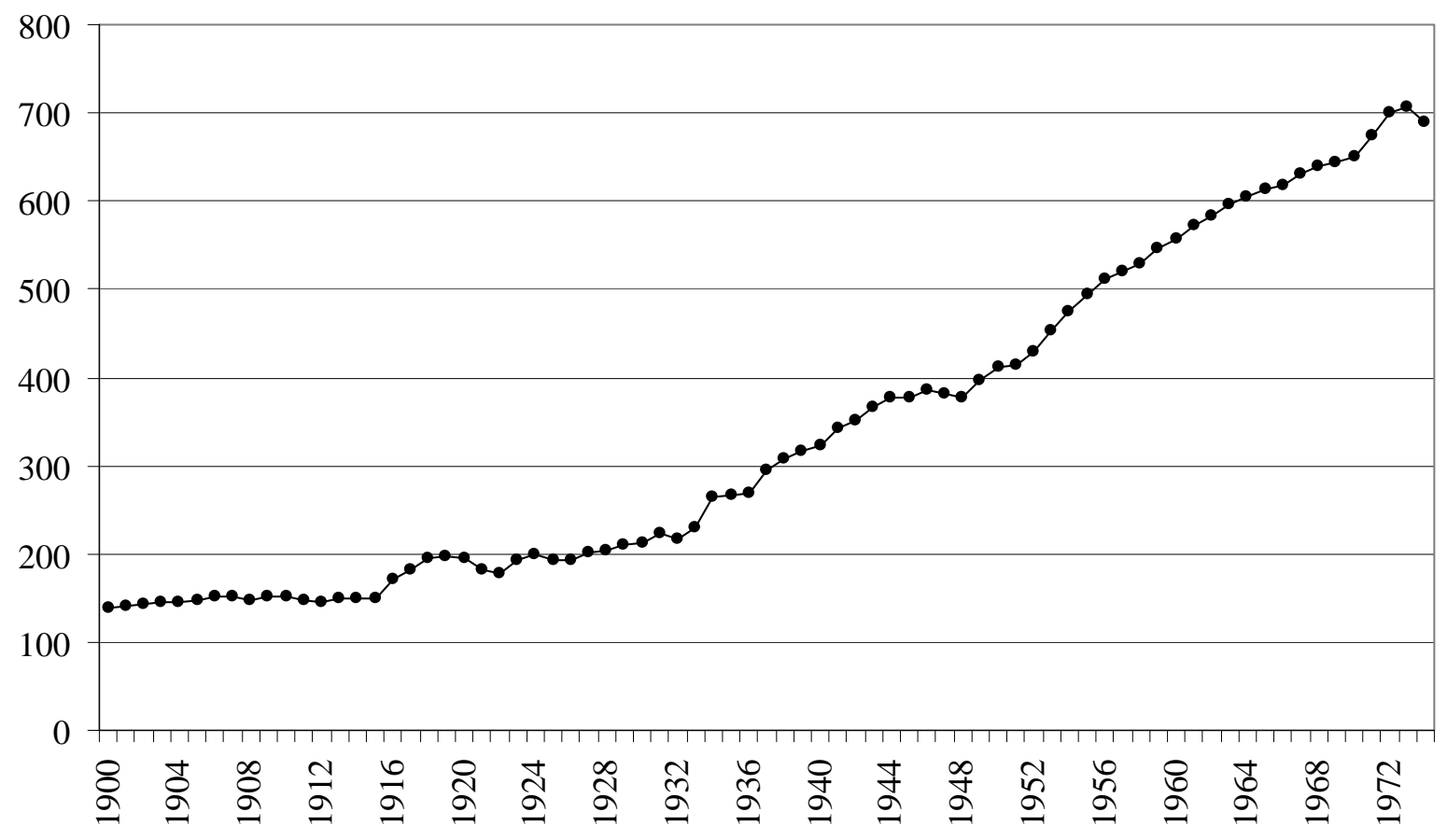

Source: The nominal wage index for unskilled labor is series Ba4218 and the cost of living series is Cc2 from Carter et al. (2006), based on David and Solar (1977). 
Figure 4. Consumer Durable Prices Relative to Producer Durable Prices, 1982=1

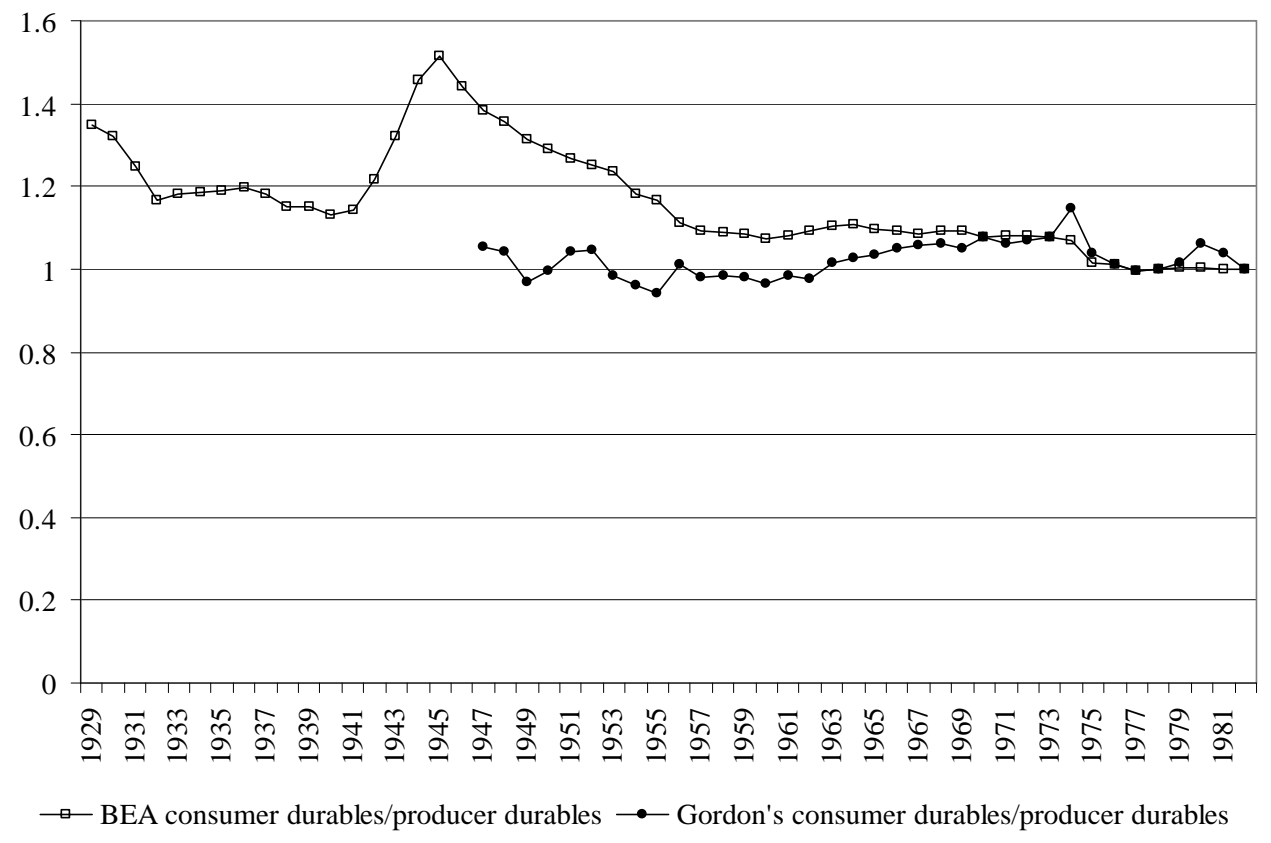

Sources: Gordon (1990) reports quality adjusted price series for consumer durables and producer durables starting in 1947 based on Sears Catalogs and Consumer Reports information for specific products. The standard BEA series are not adjusted for quality but are available for a longer period. They are drawn from Table 1.6.4, "Price Series for Gross Domestic Purchases” from the BEA website: http://www.bea.gov/national/nipaweb/Index.asp. 
Figure 5. County-level Correlations between Appliance Ownership and Fertility Rates, 1940-1960

A. 1940 Cross-sections (observations are U.S. counties)
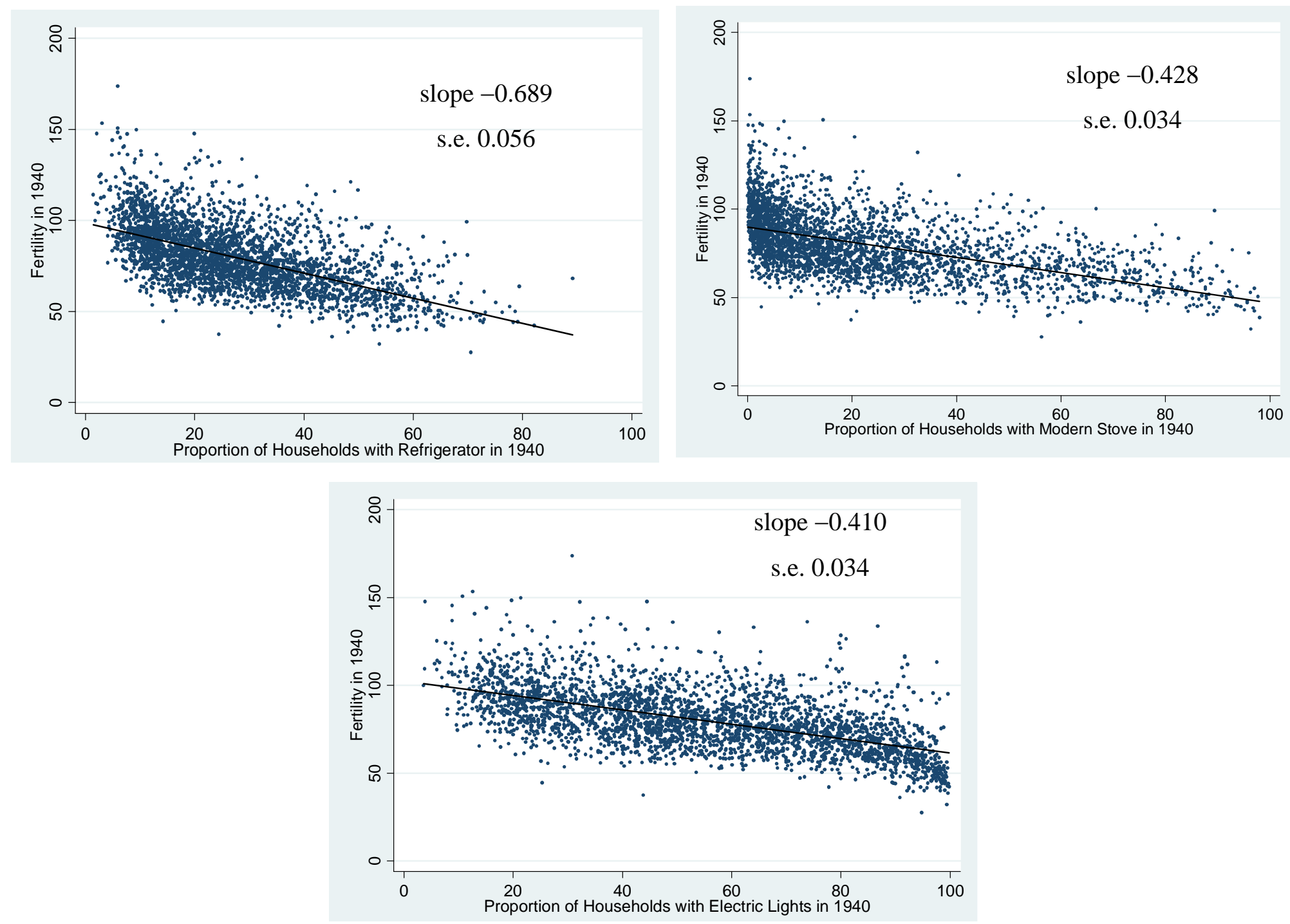
B. 1950 Cross-sections (observations are U.S. counties)
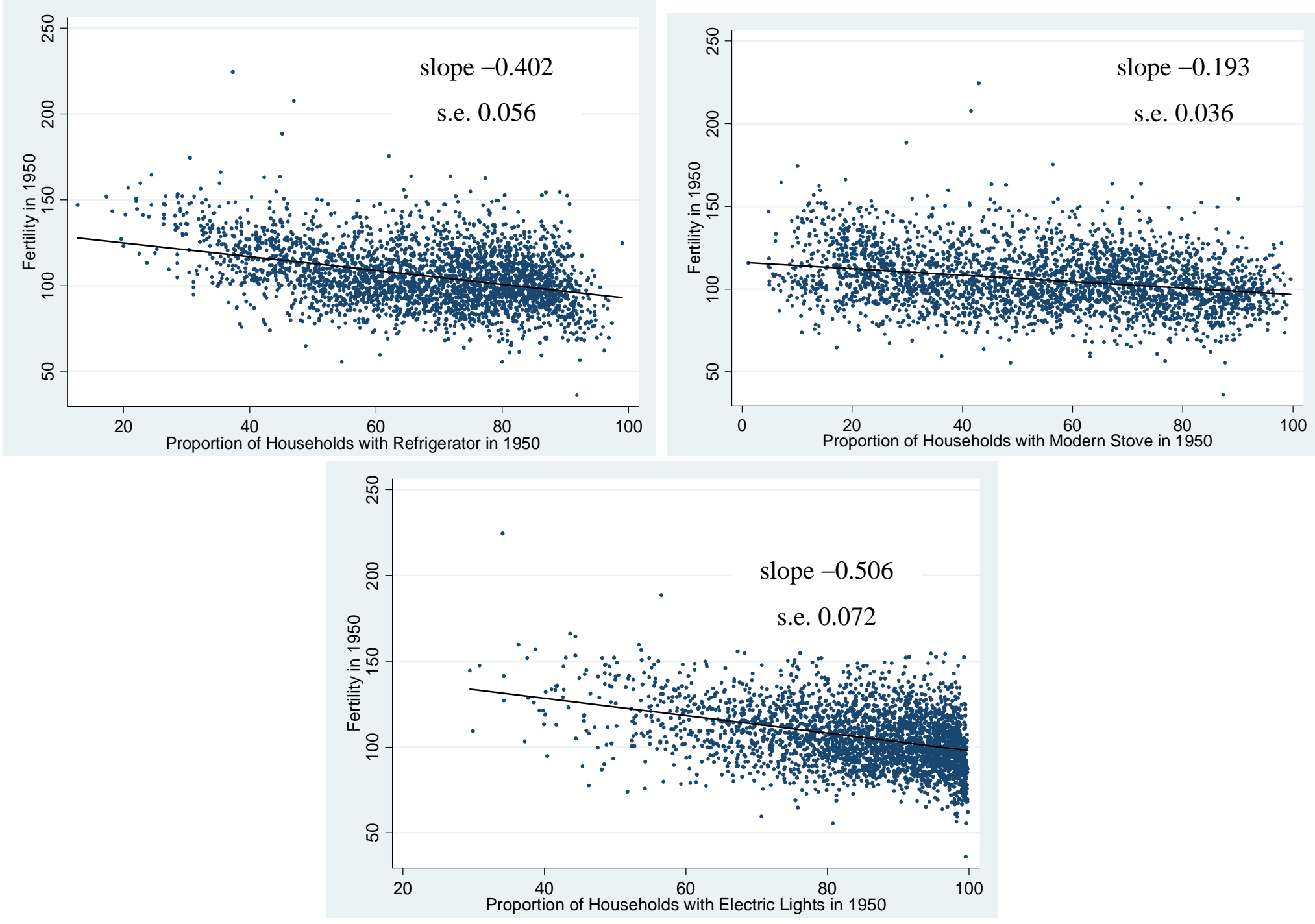


\section{1960 Cross-sections (observations are U.S. counties)}
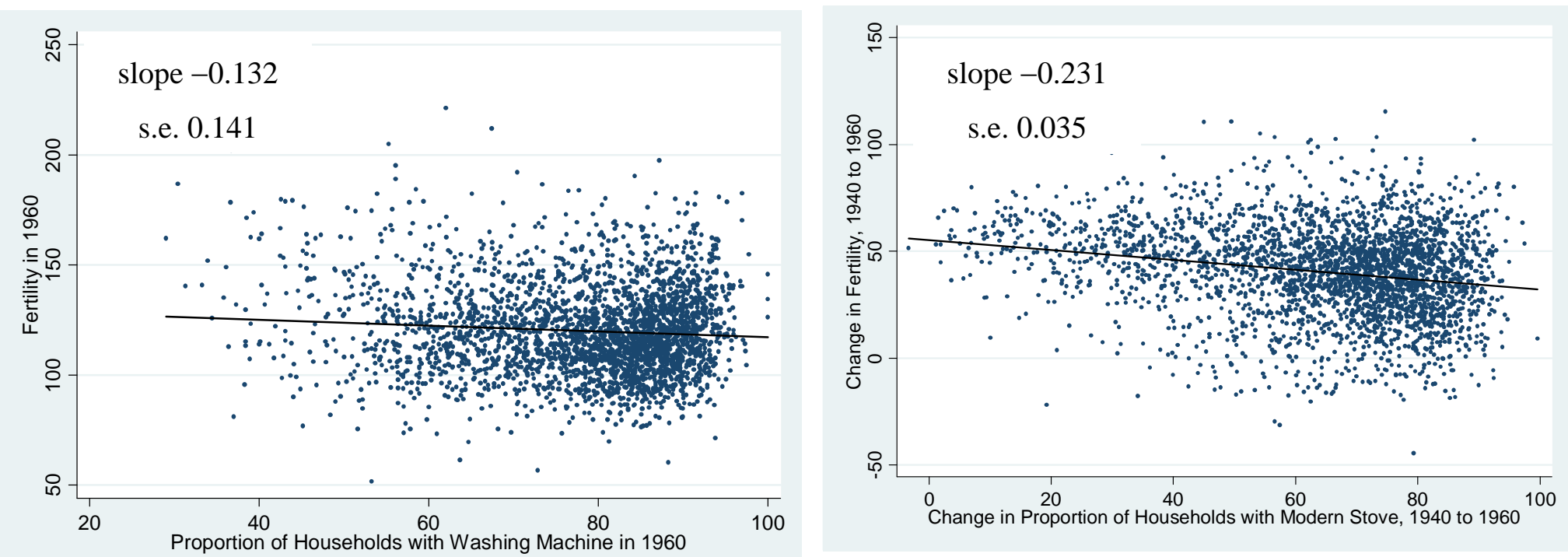
Figure 6. Changes in Fertility Rates against Changes in Appliance Ownership, 1940-1960
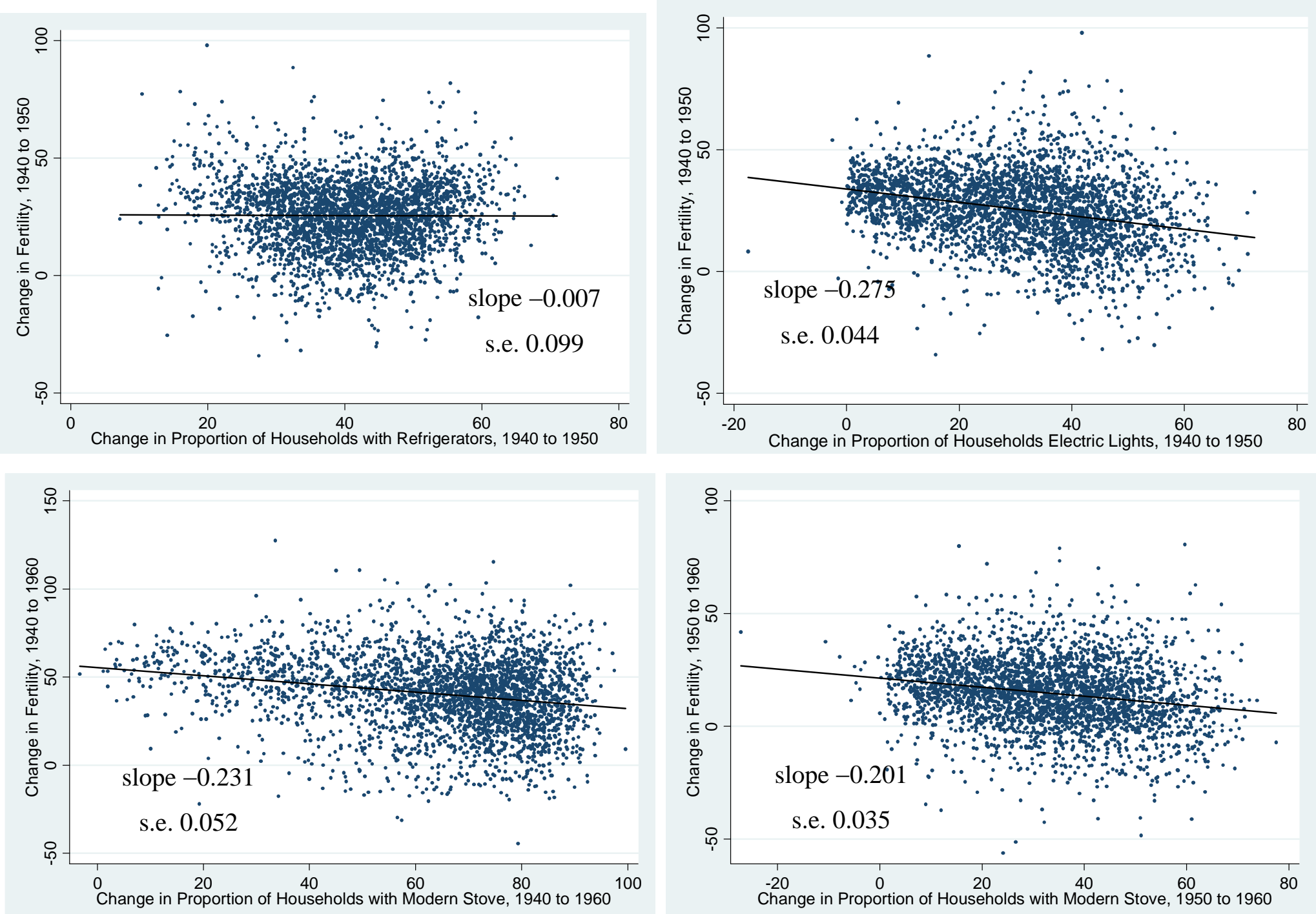
Figure 7. Mean Children Born to Likely Amish and Other U.S. Women Born 1860-1954

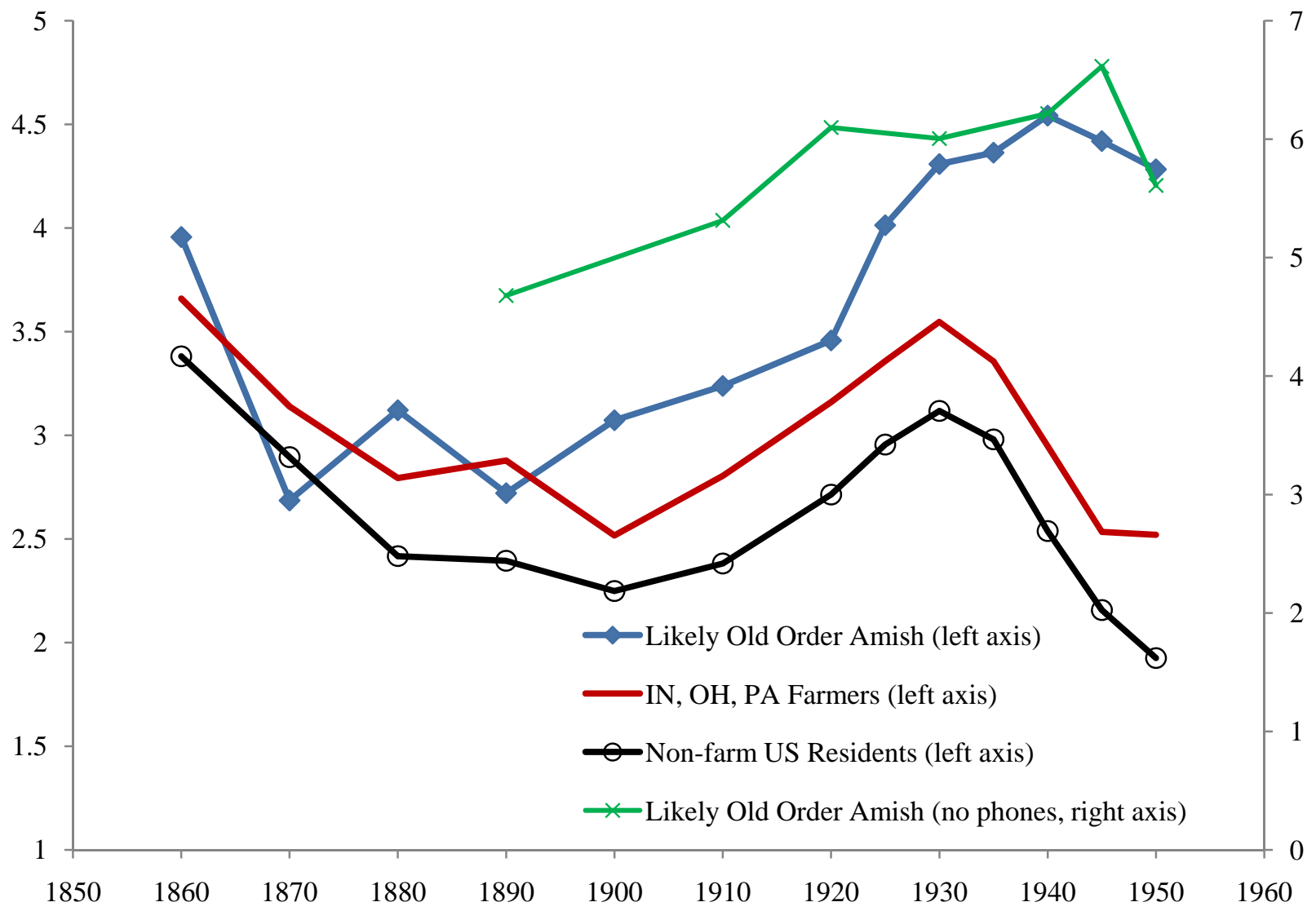

Notes: The horizontal axis represents the birth-cohort of the women, which are grouped into five or tenyear categories to maintain informative samples sizes (see data Appendix for more information). The sample is comprised of ever-married women ages 35 to 85 at the time of observation. The "Likely Old Order Amish" samples consist of women reporting that they speak Pennsylvania Dutch at home; we also plot a subsample of this group who do not have phones in their residence in the 1980 and 1990 censuses. See text and data appendix for more information.

Source: IPUMS 1940 1\% sample; pooled 1980 5\%, 1\%, 1\% Detailed Metro/Nonmetro, 1\% Urban/Rural, and 1\% Labor Market Areas samples; and pooled 1990 5\%, 1\% Metro, 3\% Elderly and 0.5\% Labor Market Areas samples of the U.S. decennial census (Ruggles et al. 2009). 


\section{Appendix 1. Household and Market Equipment Price Series}

The information presented here supplements the discussion in section I of the paper, which notes that differential trends in price series might reveal evidence of differential trends in sectorspecific technological progress. In this case, where the pace of improvement in home production technology relative to market production technology is of particular interest, one can examine the price of equipment used for home production relative to the price of equipment used for market production. We are wary of the problems associated with constructing and interpreting such data series over long periods of time, and we describe these concerns in greater detail here for completeness.

Several issues obscure the interpretation of the price series in the context of our investigation. First, the goods-of-interest are likely to have experienced rapid quality gains early in their product cycles, and an accurate price series should incorporate adjustments for these quality gains. Griliches (1971) and Gordon (1990) discuss these issues at length. The standard Bureau of Economic Analysis (BEA) price series, and therefore the quantity series that rely on them, do not make such adjustments for the period of time and the goods that are important here. Second, although Gordon (1990) provides quality-adjusted price information for the post-1947 period, there is little quality-adjusted information for earlier years. Third, important early improvements in household production, such as running water and canned goods, are not incorporated in durable good or appliance price series. Fourth, capital goods are inputs to household and market production; their prices are not measures of home or market productivity per se.

With these caveats in mind, if one takes the BEA price series at face value, it appears that the price of consumer durables, expressed relative to the price of private investment in equipment, increased sharply in the early 1940s and then gradually declined (appendix figure 1.1). It was not until 1955 that the relative price returned to its 1940 level, by which time the baby boom had nearly peaked. If we focus on the household appliance subset of consumer durables, it appears that from 1929 (when the series starts) to 1941 the series declines, then there was a sharp increase during the war, and a resumption of the pre-existing trend downward after the war. By 1950, the relative price had returned to its level in 1940, but in the meantime the fertility rate had increased from 80 to 106 (compared to 118 in 1960). Both relative price series from the BEA suggest that the baby boom was launched during a period of relatively high prices for equipment used in home production. ${ }^{1}$

\footnotetext{
${ }^{1}$ Data are drawn from Table 1.6.4. Price Series for Gross Domestic Purchases and Table 2.4.4. Price Indexes for Personal Consumption Expenditures by Type of Product, from the BEA website: http://www.bea.gov/national/nipaweb/Index.asp.
} 
Gordon (1990) shows that adjusting the prices of durable goods for changes in quality can make a large difference in the post-war price trends. This implies that the failure to incorporate quality adjustments in the BEA series can lead to large biases over long periods of time, and the biases need not be similar in the price series for different goods, so they would not simply difference out in a relative series. According to Gordon's series, there was no decline in the relative price of consumer durables from the late 1940s onward (appendix figure 1.2). There was, however, a notable decline in the relative prices of specific household appliances, with considerable variation depending on the appliance and adjustments for energy efficiency. ${ }^{2}$ Because the series start in the late 1940s, it is impossible to infer whether the relative price declines reflect a return to a pre-existing trend after a wartime price shock (as suggested by the BEA appliance price series), accelerating productivity in the production of household equipment, or neither. Moreover, it is difficult to put the qualityadjusted decline for any specific appliance into quantitative perspective without having a longer and broader set of historical examples. ${ }^{3}$

It is apparent that improvements to the price series could have serious implications for macroeconomic studies that rely on long time series of national accounts data. Rather than attempt to resolve those issues in this paper, we go on (in section II of the paper) to provide direct analyses of the correlations between actual appliance diffusion and fertility rates from 1940 to 1960. The analyses directly assess whether there is a positive link between the spread of new household technologies and the baby boom.

\footnotetext{
2 The numerator of the washing machine plot is based on the Consumer Reports series (Gordon 1990, column 5 of table 7.12), which has a larger decline than the series based on Sears catalogs. The denominator is the producer durable equipment deflator (Gordon 1990: 541).

${ }^{3}$ Assessing pre-war innovations of great value, such as running water and electric irons, would be important in this regard, as would be incorporating quality improvements in stoves, ranges, refrigerators and iceboxes.
} 
Appendix Figure 1.1. Relative Price of Consumer Durables, BEA Price Indexes, 1982=1

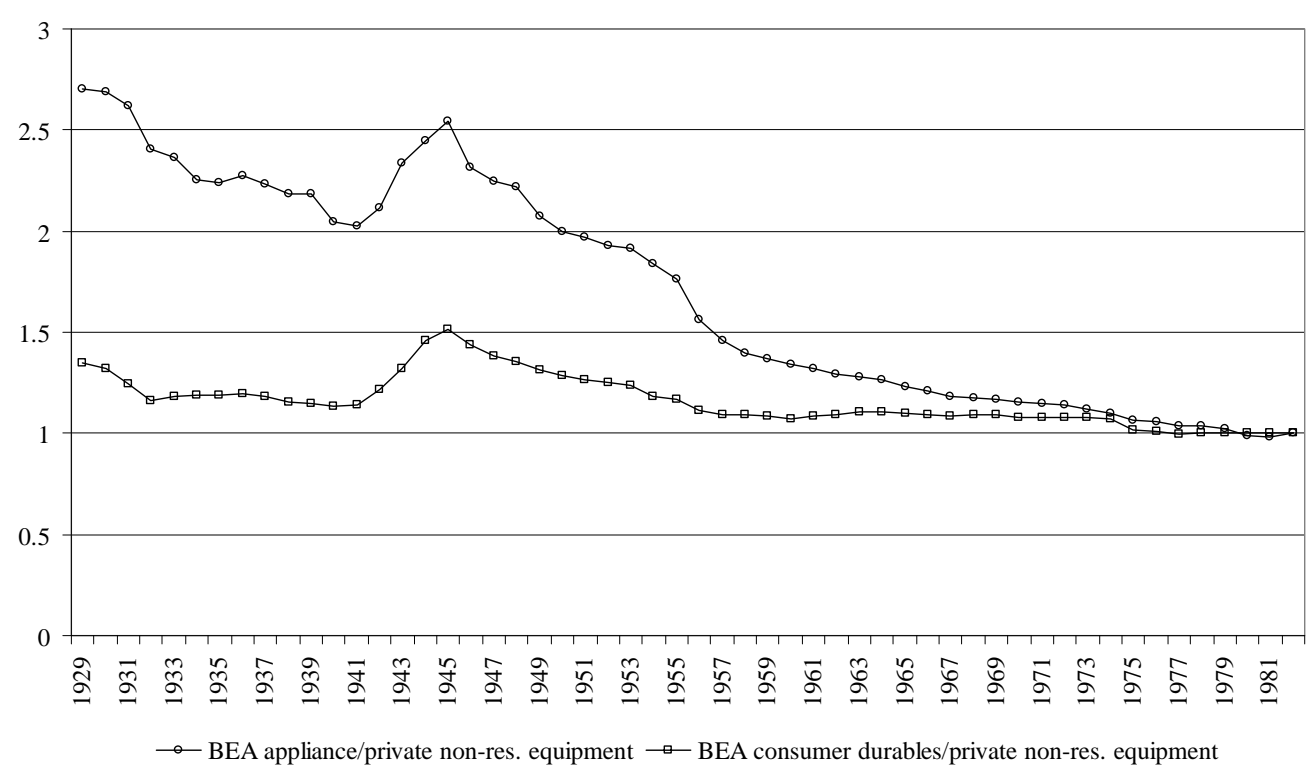

Appendix Figure 1.2. Quality-Adjusted Relative Price of Consumer Durables, Gordon Price Series, 1982=1

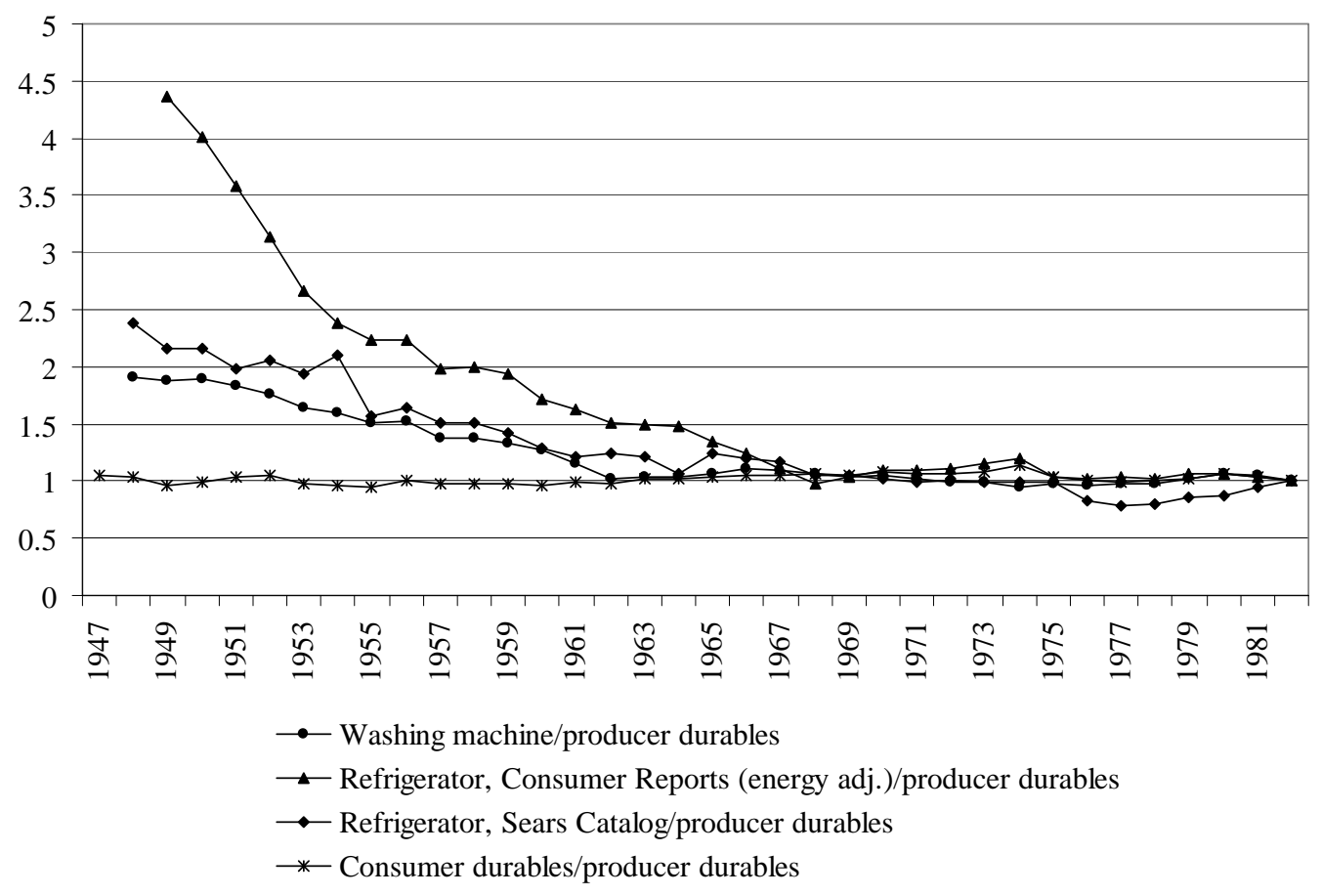




\section{Appendix 2. Data Sources}

\section{County-level data}

Data for infants per woman aged 15 to 44 and for the proportions of homes with lights (in 1940), refrigerators (in 1940 and 1950), and washing machines (1960) are from the files compiled by Michael Haines (2004). Specifically, files “32: 1940 Census I”, “33: 1940 Census II”, and “70: 1947 County Data Book” provide demographic and economic data for 1940. Files “35: 1950 Census I”, “36: 1950 Census II”, “72: 1952 County Data Book” and “73: 1956 County Data Book” provide data for 1950. Files “39: 1960 Census II”, “40: 1960 Census III”, “74: 1962 County Data Book”, and “75: 1967 County Data Book” provide data for 1960. In 1950 and 1960 the housing appliance data are based on subsamples of the full population.

We typed in the data for electric lights in 1950 and for cooking fuel in 1940, 1950, and 1960 from the published volumes of the Census of Housing, and combined that information with the data from Haines (2004) described above. For 1940, the cooking fuel figures are from Volume 2, Table 23 (for each state) of the Census of Housing. For 1950, the lighting and cooking fuel figures are from Volume 1, Table 27 (for each state) of the Census of Housing. For 1960, the cooking fuel figures are from Volume 1, Tables 16 and 29 of the Census of Housing.

The proportion of homes with "modern stoves" is the ratio of the number using electricity, utility gas, or bottled gas for the principal cooking fuel divided by the total number of units that report the cooking fuel variable; implicitly, we define those using wood, coal, kerosene, “other”, or no fuel as "not modern." The "mechanical refrigerator" variable pertains to any type of refrigeration equipment powered by electricity, gas, kerosene, or gasoline; this is distinct from an "ice box.” The "washing machine” variable that is reported in the Haines files for 1960 includes "automatic and semi-automatic” washing machines that wash, rinse, and damp dry the laundry; "washer-dryer combination” machines that wash, rinse, and fully dry the clothes in the same tub; and poweroperated “wringer or spinner” machines.

We made the following adjustments to the data from Haines (2004):

1. In 1940, the proportion of housing units with refrigerators in Raleigh County, West Virginia should be 41.8 percent, and the proportion in Washington, DC should be 79.1 percent. The median years of schooling for women and men in Cooke County, Texas should be 8.9 and 8.3 respectively. The county code for Warwick, Virginia is adjusted in 1940 to facilitate merger across datasets.

2. In 1950, approximately 40 counties with missing values for refrigerators in the 1952 County Data Book (underlying the Haines data) are listed as zeros in the Haines files. We referred back to the original Census volumes to fill in the correct figures when possible, or to set the value to 
"missing” if unavailable in the Census (replacing zero). Separately, the proportion of housing units with refrigerators in Washington, DC should be 92.0. In 1960, the figure for washing machines in Lee County, Kentucky should be 73.2 percent according to the 1962 County and City Data Book. The median property value in Milam County, Texas should be $\$ 5,400$.

Matching counties over time is imperfect due to occasional mergers and changes in boundaries. Partial county entries for Yellowstone National Park are dropped from the analysis, as are counties/territories in Hawaii and Alaska. Excluding counties with reported changes of more than 5 square miles does not change the qualitative results from tables 3 and 4 . The coefficient in panel A, column 3 (refrigerators, 1940-50) increases in magnitude from -0.101 (s.e. $=0.094$ ) to -0.121 (s.e.=0.091); the coefficient in panel B, column 3 (stoves 1940-1960) falls in magnitude from -0.088 (s.e.=0.049) to -0.076 (s.e.=0.051). The coefficient change for electric lighting (1940-50) in table 4 is from -0.182 to -0.187 (s.e. $=0.054$ in both cases).

In 1960, approximately 15 percent of counties have a bottom code for median property values of $\$ 5,000$ in the census data. The results in the text are not sensitive to resetting these observations to $\$ 3,750$ (75\% of 5,000). In table 2, panel C, column 3, the coefficient on washing machines falls from 0.068 to 0.057 (s.e. $=0.069$ in both cases); the coefficient on modern stoves falls from -0.309 (s.e. $=0.113$ ) to -0.327 (s.e.=0.116). In table 3, panel B, column 3, the coefficient on modern stoves (1940-60) falls from -0.088 to -0.093 (s.e. $=0.50$ in both cases); in panel C, column 3, the coefficient on modern stoves (1950-60) increases from -0.044 to -0.043 (s.e. $=0.053$ in both cases).

\section{State-level, annual electricity data}

The numerator for the "mean exposure to electricity" variable is constructed from the Edison Electrical Institute (EEI) publication, Statistical Bulletin. The Bulletin provides annual state-level reports of the number of residential electrical customers from 1925 to 1960 . In the EEI data, Maryland and Washington DC customers are always counted together. North Carolina and South Carolina customers are often counted together, and for consistency we used these larger units of aggregation for all years.

To calculate the denominator, we used the housing unit counts from the census, which we interpolated between dates with constant growth rates. Then, we divided the EEI customer counts by the Census of Housing counts of families (in 1920 and 1930) or occupied dwelling units (in 1940, 1950, and 1960) in each state to estimate the proportion of families with electrical service. The figures for the denominator are consistent with the housing unit counts in Historical Statistics of the United States (Carter et al., 2006). Kenneth Snowden discusses the comparability of housing count 
data across census years in Volume 4 of Historical Statistics ( 4-500 and 4-501): "Before 1940 the census enumerated "families" and not housing unit... However, the two concepts are closely related: a census family was defined in 1930 as a single person living alone, a small group of unrelated persons sharing living accommodations, or, more normally, a group of related persons who live together as one household. Despite differences in terminology, therefore, the basic notion of a family, dwelling unit, or housing unit has provided essentially comparable measures of the residential housing stock since 1890.”

On occasion, the ratio of residential customers from EEI to housing units from the Census slightly exceeds unity (in approximately 10 percent of state-year cells from 1925 to 1960). Nearly all such cases (84 percent) occur between 1950 and 1960 when the true rate of electrification is likely to be close to 100 percent for some states. We have left these values in place rather than making ad hoc adjustments to the underlying data.

\section{Amish data}

The Amish fertility series presented in the text combine information from several different IPUMS samples to maximize sample size. This combined sample includes the 1940 1\% sample; pooled 1980 5\%, 1\%, 1\% Detailed Metro/Nonmetro, 1\% Urban/Rural, and 1\% Labor Market Areas samples; and pooled 1990 5\%, 1\% Metro, 3\% Elderly and 0.5\% Labor Market Areas samples of the U.S. decennial census (Ruggles et al. 2009). For comparison groups we select non-Pennsylvania Dutch speaking respondents from farms in Pennsylvania, Ohio, and Indiana (the main settlement areas of the Amish) and a set of non-farm households from throughout the US (to show the general population's baby boom). As described in the main text, we check the robustness of trends by excluding respondents with telephones in the 1980 and 1990 censuses and also excluding Pennsylvania Dutch speakers residing in Pennsylvania. Appendix table 2.1 reports the estimates and sample sizes underlying figure 7.

The main criterion for selection into the sample of potential Amish respondents is whether Pennsylvania Dutch is the respondent's primary language spoken at home (1980 and 1990) or "mother tongue" (1940 census). There is a close link between Amish-status and the use of Pennsylvania Dutch (also known as Pennsylvania German) as one’s primary language. This claim is based upon several external sources.

i. We contacted a contributor to the linguistics literature on the Pennsylvania German language, Karen Johnson-Weiner, a Professor of Anthropology at SUNY-Potsdam. She confirmed that the overwhelming majority of Pennsylvania German speakers, the term used by linguists to refer to Pennsylvania Dutch speakers, are Old Order Amish or from smaller groups of 
conservative "horse-and-buggy” Old Order Mennonites [specifically the Stauffer and Wenger Mennonite groups]. The most easily and widely accessible source of reliable information on the Amish is Elizabethtown College's Amish Studies website, which is supported by the Young Center for Anabaptist and Pietist Studies. As of May 2010, the website notes that "Regardless of where they live, the Amish speak the Pennsylvania German dialect (popularly known as Pennsylvania Dutch), except in a few communities where they speak a Swiss Dialect” (http://www2.etown.edu/amishstudies/FAQ.asp). It also notes that "Although the Amish originally comprised only a small minority of the Pennsylvania German-speaking population [in the 1700s], they and the Old Order Mennonites are the last groups to use the language actively and pass it on to their children” (http://www2.etown.edu/amishstudies/Language.asp). Our reading suggests that when scholars attempt to estimate the number of Pennsylvania Dutch speakers in the world, they start by estimating the number of Old Order Amish; other groups are comparatively small. In sum, there is no controversy in the claim that Pennsylvania Dutch is the primary language of the Amish, and that the Amish comprise the vast majority of speakers of Pennsylvania Dutch.

ii. We also undertook additional reading of the linguistics literature on Pennsylvania German. Huffines (1980) notes: "Pennsylvania German is the main language used within plain families and communities, the language which is passed on to children as their mother tongue” and "The use of Pennsylvania German among non-plain Pennsylvania Germans is diminishing rapidly. Most of the non-plain Pennsylvania Germans learn Pennsylvania German as a second language if they learn it at all” (p. 352). ${ }^{4}$ Moelleken notes, "From all accounts the cluster speakers have already assumed the dominant role in the Pennsylvania German-speaking landscape and will, in all likelihood, all but displace the other groups in a few years” (1988, p. 107)..$^{5}$ Overall, our reading suggests a rapid decline in the use of Pennsylvania German among non-Amish residents of Pennsylvania starting in the early 1900s at the latest. Like many other ethnic groups in the early 1900s, non-Amish adult speakers of Pennsylvania Dutch stopped speaking and teaching the language to their children (who attended English-speaking schools) because of perceptions about the importance of learning and using English. This may have been heightened by anti-German sentiment associated with World War I and II. Daily and primary use of the language has all but died in non-Amish communities, and even among those non-Amish who have rudimentary

\footnotetext{
${ }^{4}$ In this context, "plain” families are members of conservative, Old Order sects of Amish and Mennonites.

5 "Cluster speakers" of Pennsylvania Dutch are those apart from mainstream society due to their religious beliefs. The Amish are the largest such group.
} 
knowledge of the Pennsylvania Dutch language, nearly all view English as their first language.

We find the information above to be helpful in confirming our interpretation of the Pennsylvania Dutch language variable as a strong correlate of Old Order Amish religion, but we have pursued an additional robustness check: Suppose that non-Amish Pennsylvania Dutch speakers contaminate our sample. To the extent that non-Amish Pennsylvania Dutch speakers are in our sample, nearly all should reside in Pennsylvania. Therefore, we constructed an IPUMS-based series that excludes everyone from Pennsylvania. Appendix figure 2.1 shows that this restriction does not change our conclusions. This robustness check squares nicely with other checks reported in the paper.

Finally, it is worth noting that our work with the IPUMS data offers confirmation of facts that were originally generated in a completely independent literature on the demographic history of Amish—a literature that uses genealogical records in which there is no ambiguity about Amish status. This literature is discussed and cited in section III of the paper. 
Appendix Figure 2.1. Baby Boom among Pennsylvania Dutch Speakers Outside of Pennsylvania

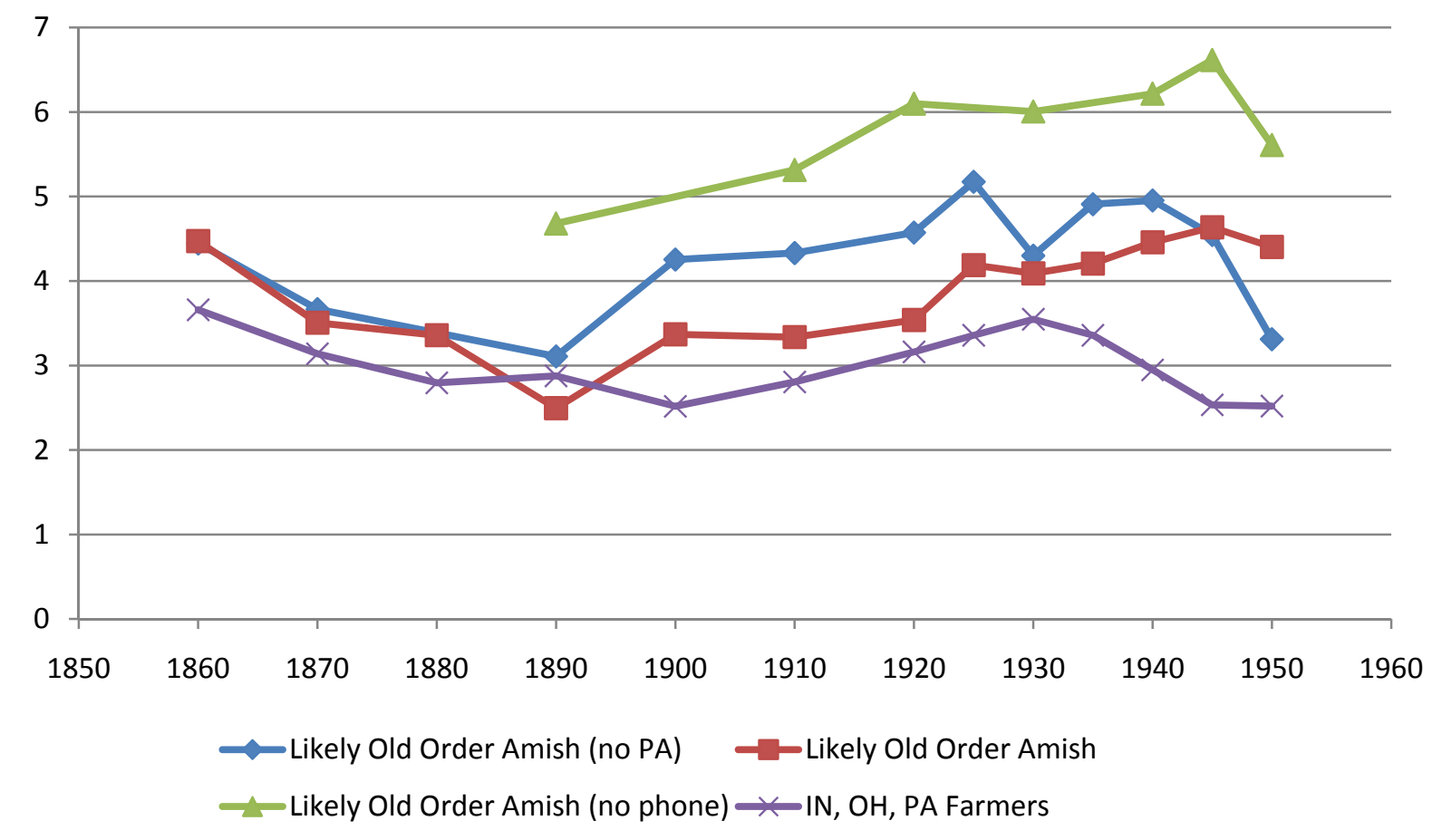


Appendix Table 2.1. Summary Statistics for the Likely Old Order Amish Sample

\begin{tabular}{|c|c|c|c|c|}
\hline $\begin{array}{l}\text { Birth } \\
\text { Cohort }\end{array}$ & Likely Amish & $\begin{array}{l}\text { Likely Amish } \\
\text { (no phones) }\end{array}$ & $\begin{array}{l}\text { Farm residents in } \\
\text { IN, OH, PA }\end{array}$ & $\begin{array}{l}\text { Non-farm U.S. } \\
\text { residents }\end{array}$ \\
\hline \multirow[t]{3}{*}{1860} & 3.96 & & 3.66 & 3.38 \\
\hline & $(0.513)$ & & $(0.236)$ & $(0.038)$ \\
\hline & {$[23]$} & & {$[141]$} & {$[6,204]$} \\
\hline \multirow[t]{3}{*}{1870} & 2.686 & & 3.14 & 2.89 \\
\hline & $(0.490)$ & & $(0.143)$ & $(0.025)$ \\
\hline & {$[35]$} & & {$[331]$} & {$[12,410]$} \\
\hline \multirow[t]{3}{*}{1880} & 3.121 & & 2.79 & 2.42 \\
\hline & $(0.464)$ & & $(0.12)$ & $(0.019)$ \\
\hline & [33] & & {$[471]$} & {$[15,878]$} \\
\hline \multirow[t]{3}{*}{1890} & 2.721 & $4.680 *$ & 2.88 & 2.39 \\
\hline & $(0.261)$ & $(0.554)$ & $(0.093)$ & $(0.007)$ \\
\hline & [104] & {$[50]$} & {$[704]$} & {$[120,368]$} \\
\hline \multirow[t]{3}{*}{1900} & 3.072 & & 2.52 & 2.25 \\
\hline & $(0.141)$ & & $(0.054)$ & $(0.003)$ \\
\hline & {$[426]$} & & {$[1,622]$} & {$[536,506]$} \\
\hline \multirow[t]{3}{*}{1910} & 3.238 & 5.314 & 2.80 & 2.38 \\
\hline & $(0.107)$ & $(0.385)$ & $(0.038)$ & $(0.002)$ \\
\hline & {$[769]$} & {$[105]$} & {$[3,186]$} & {$[1,078,488]$} \\
\hline \multirow[t]{3}{*}{1920} & 3.458 & $6.098 *$ & 3.16 & 2.71 \\
\hline & $(0.169)$ & $(0.36)$ & $(0.045)$ & $(0.003)$ \\
\hline & {$[365]$} & [132] & {$[2,292]$} & {$[686,069]$} \\
\hline \multirow[t]{3}{*}{1925} & 4.013 & & 3.36 & 2.96 \\
\hline & $(0.167)$ & & $(0.044)$ & $(0.003)$ \\
\hline & {$[377]$} & & {$[2,451]$} & {$[707,994]$} \\
\hline \multirow[t]{3}{*}{1930} & 3.308 & $6.005^{*}$ & 3.55 & 3.12 \\
\hline & (0.189) & $(0.281)$ & $(0.044)$ & $(0.003)$ \\
\hline & [318] & [187] & {$[2,376]$} & {$[671,161]$} \\
\hline \multirow[t]{3}{*}{1935} & 4.363 & & 3.36 & 2.98 \\
\hline & $(0.192)$ & & $(0.04)$ & $(0.002)$ \\
\hline & [300] & & {$[2,314]$} & {$[683,298]$} \\
\hline \multirow[t]{3}{*}{1940} & 4.542 & 6.216 & 2.95 & 2.54 \\
\hline & (0.188) & (0.324) & $(0.037)$ & $(0.002)$ \\
\hline & [332] & [139] & {$[2,381]$} & {$[815,073]$} \\
\hline \multirow[t]{3}{*}{1945} & 4.419 & 6.614 & 2.53 & 2.16 \\
\hline & $(0.240)$ & $(0.435)$ & $(0.046)$ & $(0.002)$ \\
\hline & [210] & [70] & {$[1,303]$} & {$[591,659]$} \\
\hline \multirow[t]{3}{*}{1950} & 4.283 & 5.609 & 2.52 & 1.93 \\
\hline & $(0.229)$ & $(0.361)$ & $(0.055)$ & $(0.002)$ \\
\hline & [205] & [92] & {$[1,067]$} & {$[585,480]$} \\
\hline \multirow[t]{3}{*}{ Total } & 3.757 & 5.888 & 3.033 & 2.567 \\
\hline & $(0.054)$ & (0.139) & $(0.015)$ & $(0.001)$ \\
\hline & {$[3,497]$} & [775] & {$[20,639]$} & {$[6,510,588]$} \\
\hline
\end{tabular}


Notes: The table entries are the mean number of children ever born, the standard error of the mean in parenthesis, and the number of observations in brackets. Birth cohorts are grouped into five or tenyear categories to maintain informative samples sizes. *The cohort labeled 1890-99 for the likely Old Amish (no phones) corresponds to the 1890 to 1909 cohort. The younger cohorts of the likely Amish (no phones) are grouped into ten year cohorts, so the cohorts labeled 1920-24 and 1930-34 correspond to the ten-year groupings 1920-29 and 1930-39, respectively. For sample definitions and source information, see text and figure 7 notes. 


\section{Appendix 3. Additional Results}

This appendix reports additional results from regressions of county-level fertility rates on appliance ownership and electrification.

\section{Median regressions}

Footnote 8 of the paper reports that median regressions yield results that are similar to those from the paper's OLS regression specifications, which are reported in tables 2, 3, and 4. For comparison, the median regression results are reported in appendix tables 3.1, 3.2, and 3.3 presented below.

\section{Instrumental variable regressions}

Because access to the electrical service is related to the use of modern appliances, it is a potential instrumental variable for appliance ownership. At the request of a referee, we ran regressions of fertility on appliances (refrigerators or modern stoves), using electricity in 1940 and 1950 as an instrumental variable. This yields uniformly negative coefficients on appliance diffusion. Results are reported in appendix table 3.4 below. Standard errors are adjusted for clustering at the state level and reported in square brackets. F-statistics on the excluded instrument from the firststage regression are reported in curved brackets. In some cases the IV results are close to the OLS results in tables 2 and 3 of the paper, but in other cases the IV results are much larger in magnitude (i.e., much more negative). We are not fully convinced that this is a valid IV strategy because it is hard to rule out the possibility that electrification had a direct effect on fertility through its effect on the local economy.

\section{Additional control variables}

To address concerns about cross-county differences in the distribution of income across families, we have re-run the paper's county-level regressions with additional control variables that measure the proportions of families with "low" and "high" income. The 1950 census reports the proportion of families with income under \$2,000 and proportion of families with income above $\$ 5,000$ in each county. The 1960 census reports the proportion of families below $\$ 3,000$ and the proportion above $\$ 10,000$. Regression results are reported in appendix table 3.5 for both the original specification (as in the paper) and the expanded specification (with low and high income). Adding these variables has a negligible effect on the results. There is not comparable information for the 1940 census, which did not ascertain family income or its distribution. 
Appendix Table 3.1. Quantile Regressions of Fertility on Appliances in U.S. Counties, Cross-Sectional Specifications, 1940-1960

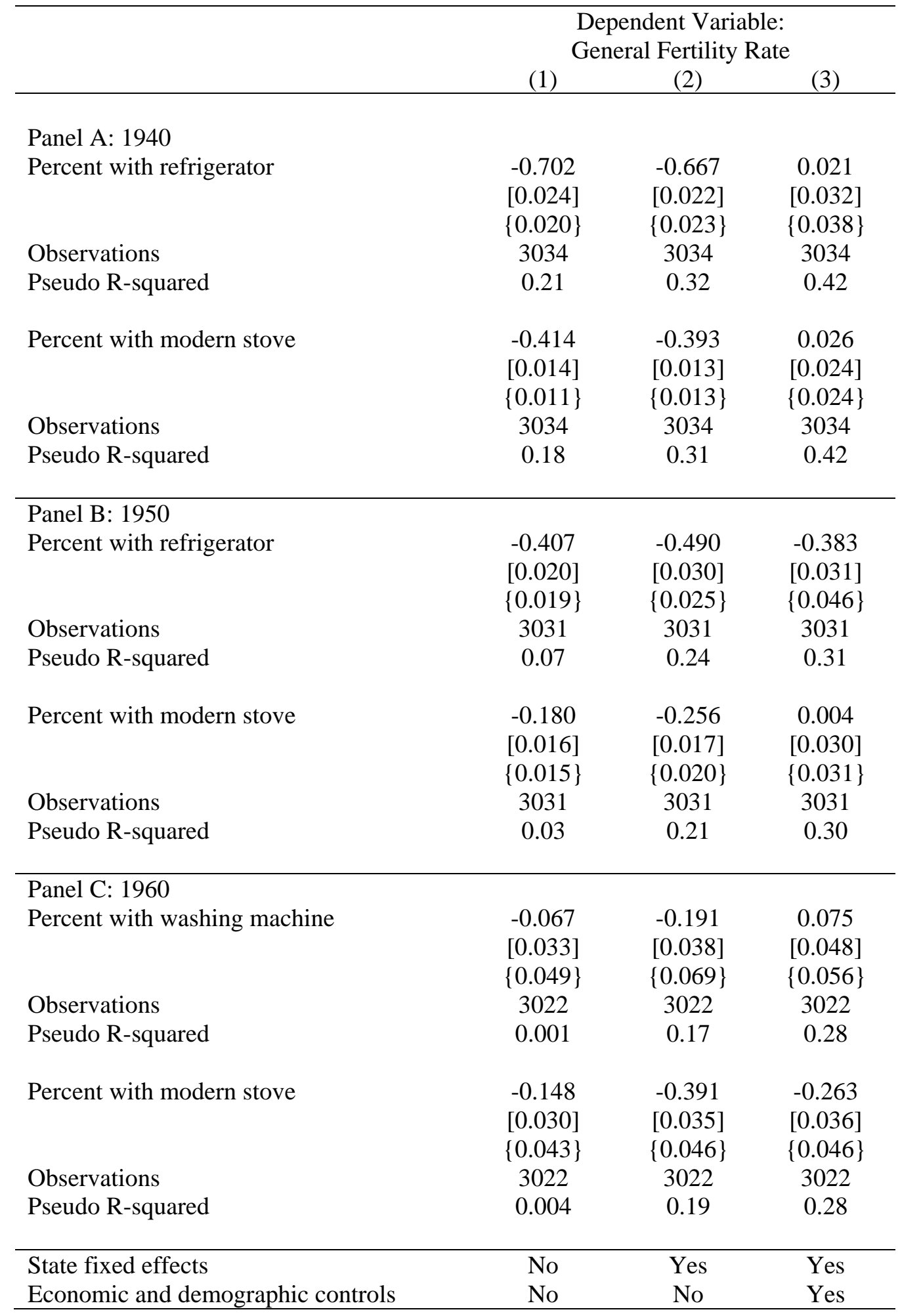

Notes: Each point estimate is from a separate median regression corresponding to equation 1 (crosssectional specification). Stata's default method for calculating standard errors is based on Koenker and Bassett (1992) and Rogers (1993); these are reported in square brackets. Bootstrapped standard 
errors (1,000 repetitions) are reported in curved brackets; the method is based on Gould (1992, 1997). The dependent variable is the number of infants (under 1 year) per thousand women ages 15 to 44. A "modern stove" is defined to use electricity or gas (not wood, coal, or kerosene). The unit of observation is a county. The covariates in column 3 include the urban proportion of the county's population, log population density, nonwhite proportion of the county's population, proportion of employment in agriculture and manufacturing (separately), median years of schooling for those over age 24, log of median property value, and the proportion of women in the labor force. The 1950 and 1960 specifications also control for log median family income (this variable is unavailable in 1940). The urban variable generally measures the proportion of the population residing in incorporated places with more than 2,500 residents. The density measure is the log of residents per square mile. Nonwhite includes black and "other" racial categories. The proportion of workers employed in agricultural and manufacturing industries are expressed relative to total employment. The percent of women in the labor force is the ratio of all women in the labor force divided by the number of women over age 14. The median schooling variable in the 1940 table is for women, whereas in 1950 and 1960 it is for both men and women. Observations with missing values for any economic or demographic control variable are dropped to maintain a consistent sample across specifications.

Sources: Data for refrigerators, washing machines, and covariates are from Haines (2004). Data on the type of cooking fuel, which are used to define "modern stoves," were entered from the published Census of Housing volumes (U.S. Department of Commerce 1943, 1953, 1963). 
Appendix Table 3.2. Quantile Regressions of Fertility on Appliances in U.S. Counties, Difference Specifications, 1940-1960

\begin{tabular}{lccc}
\hline & \multicolumn{3}{c}{ Dependent Variable: } \\
& $(1)$ & $(2)$ & $(3)$ \\
\hline & & & \\
Panel A: Refrigerators 1940-50 & -0.042 & -0.242 & -0.055 \\
$\Delta$ Percent with refrigerator & {$[0.032]$} & {$[0.041]$} & {$[0.032]$} \\
& $\{0.035\}$ & $\{0.038\}$ & $\{0.042\}$ \\
Observations & 3023 & 3023 & 3023 \\
Pseudo R-squared & 0.00 & 0.12 & 0.18 \\
\hline & & & \\
Panel B: Modern stoves, 1940-60 & & & \\
$\Delta$ Percent with modern stove & -0.265 & -0.333 & -0.091 \\
& {$[0.021]$} & {$[0.020]$} & {$[0.029]$} \\
& $\{0.021\}$ & $\{0.023\}$ & $\{0.027\}$ \\
Observations & 2990 & 2990 & 2990 \\
Pseudo R-squared & 0.04 & 0.18 & 0.26 \\
\hline & & & \\
Panel C: Modern stoves, 1950-60 & & & \\
$\Delta$ Percent with modern stove & -0.236 & -0.216 & -0.056 \\
& {$[0.020]$} & {$[0.026]$} & {$[0.023]$} \\
& $\{0.020\}$ & $\{0.027\}$ & $\{0.033\}$ \\
Observations & 2990 & 2990 & 2990 \\
Pseudo R-squared & 0.03 & 0.11 & 0.15 \\
\hline State fixed effects & No & Yes & Yes \\
Economic and demographic controls & No & No & Yes \\
\hline
\end{tabular}

Notes: Each point estimate is from a separate median regression corresponding to equation 2 (difference specification). Stata's default method for calculating standard errors is based on Koenker and Bassett (1992) and Rogers (1993); these are reported in square brackets. Bootstrapped standard errors (1,000 repetitions) are reported in curved brackets; the method is based on Gould (1992, 1997). The dependent variable is the change in the number of infants (under 1 year) per thousand women ages 15 to 44 between two census years at the county-level. The covariates in column 3 include the change in urban proportion of the county's population, the change in log population density, the change in nonwhite proportion of the county's population, the change in proportion of employment in agriculture and manufacturing (separately), the change in median years of schooling for those over age 24, the change in log of median property value, and the change in the proportion of women in the labor force. Urban, density, nonwhite, employment and labor force variables are defined as in table 2's notes. In this table, for better comparability with the variables available in 1950 and 1960 (which include both men and women), the schooling variable in 1940 is the average of the median schooling values for men and women. When necessary, observations with missing values are dropped to maintain a consistent sample across specifications.

Sources: Data for refrigerators, washing machines, and covariates are from Haines (2004). Data on the type of cooking fuel were entered from the published census volumes in each year as described in the data appendix. 
Appendix Table 3.3. Quantile Regressions of Period Fertility on Electrical Service, 1940-1950

\begin{tabular}{|c|c|c|c|}
\hline & \multicolumn{3}{|c|}{$\begin{array}{l}\text { Dependent Variable: } \\
\text { General Fertility Rate }\end{array}$} \\
\hline & $(1)$ & $(2)$ & $(3)$ \\
\hline \multicolumn{4}{|l|}{ Panel A: Fertility cross section, 1940} \\
\hline \multirow[t]{3}{*}{ Percent with electric lights } & -0.419 & -0.529 & -0.174 \\
\hline & {$[0.011]$} & [0.013] & [0.029] \\
\hline & $\{0.011\}$ & $\{0.015\}$ & $\{0.032\}$ \\
\hline Observations & 3034 & 3034 & 3034 \\
\hline Pseudo R-squared & 0.21 & 0.36 & 0.42 \\
\hline \multicolumn{4}{|l|}{ Panel B: Fertility cross section, 1950} \\
\hline \multirow[t]{3}{*}{ Percent with electric lights } & -0.518 & -0.565 & -0.360 \\
\hline & {$[0.028]$} & [0.022] & [0.041] \\
\hline & $\{0.038\}$ & $\{0.028\}$ & $\{0.055\}$ \\
\hline Observations & 3031 & 3031 & 3031 \\
\hline Pseudo R-squared & 0.07 & 0.25 & 0.31 \\
\hline \multicolumn{4}{|l|}{ Panel C: Fertility change, 1940-1950 } \\
\hline \multirow[t]{3}{*}{$\Delta$ Percent with electric lights } & -0.289 & -0.351 & -0.188 \\
\hline & {$[0.021]$} & {$[0.026]$} & [0.022] \\
\hline & $\{0.018\}$ & $\{0.024\}$ & $\{0.036\}$ \\
\hline Observations & 3023 & 3023 & 3023 \\
\hline Pseudo R-squared & 0.05 & 0.15 & 0.18 \\
\hline State fixed effects & No & Yes & Yes \\
\hline Economic and demographic controls & No & No & Yes \\
\hline
\end{tabular}

Notes and sources: See appendix table 3.1. We compiled the data for electric lights in 1950 from the published volumes of the Census of Housing (U.S. Department of Commerce 1953); the 1940 electric light data are from Haines (2004). 
Appendix Table 3.4. Using Electric Lights to IV for Appliance Ownership in 1940 and 1950

\begin{tabular}{|c|c|c|c|c|c|c|}
\hline $\begin{array}{l}\text { Panel A: Cross Section } \\
\text { Regressions, } \\
\text { Corresponding } \\
\text { Specifications in Table } 2\end{array}$ & $\begin{array}{l}\text { Table 2, } \\
\text { Col. 1, } \\
\text { OLS }\end{array}$ & $\begin{array}{l}\text { Table 2, } \\
\text { Col. 1, } \\
\text { IV }\end{array}$ & $\begin{array}{l}\text { Table 2, } \\
\text { Col. 2, } \\
\text { OLS }\end{array}$ & $\begin{array}{l}\text { Table 2, } \\
\text { Col. 2, } \\
\text { IV }\end{array}$ & $\begin{array}{l}\text { Table 2, } \\
\text { Col. 3, } \\
\text { OLS }\end{array}$ & $\begin{array}{l}\text { Table 2, } \\
\text { Col 3, } \\
\text { IV }\end{array}$ \\
\hline 1940 Refrigerator & $\begin{array}{c}-0.689 \\
{[0.056]}\end{array}$ & $\begin{array}{c}-0.800 \\
{[0.060]} \\
\{933.06\}\end{array}$ & $\begin{array}{l}-0.665 \\
{[0.067]}\end{array}$ & $\begin{array}{c}-0.858 \\
{[0.071]} \\
\{1161.29\}\end{array}$ & $\begin{array}{c}0.017 \\
{[0.050]}\end{array}$ & $\begin{array}{l}-0.414 \\
{[0.162]} \\
\{58.03\}\end{array}$ \\
\hline 1940 Modern Stove & $\begin{array}{l}-0.428 \\
{[0.034]}\end{array}$ & $\begin{array}{c}-0.638 \\
{[0.051]} \\
\{258.11\}\end{array}$ & $\begin{array}{l}-0.410 \\
{[0.038]}\end{array}$ & $\begin{array}{c}-0.672 \\
{[0.075]} \\
\{219.11\}\end{array}$ & $\begin{array}{c}0.029 \\
{[0.034]}\end{array}$ & $\begin{array}{c}-1.031 \\
{[0.946]} \\
\{1.85\}\end{array}$ \\
\hline 1950 Refrigerator & $\begin{array}{c}-0.402 \\
{[0.056]}\end{array}$ & $\begin{array}{c}-0.459 \\
{[0.060]} \\
\{1017.90\}\end{array}$ & $\begin{array}{c}-0.483 \\
{[0.057]}\end{array}$ & $\begin{array}{c}-0.589 \\
{[0.058]} \\
\{777.55\}\end{array}$ & $\begin{array}{c}-0.401 \\
{[0.104]}\end{array}$ & $\begin{array}{c}-0.659 \\
{[0.142]} \\
\{382.83\}\end{array}$ \\
\hline 1950 Modern Stove & $\begin{array}{l}-0.193 \\
{[0.036]}\end{array}$ & $\begin{array}{c}-0.397 \\
{[0.061]} \\
\{378.25\} \\
\end{array}$ & $\begin{array}{l}-0.246 \\
{[0.033]}\end{array}$ & $\begin{array}{c}-0.519 \\
{[0.067]} \\
\{211.49\} \\
\end{array}$ & $\begin{array}{c}0.004 \\
{[0.049]}\end{array}$ & $\begin{array}{c}-2.335 \\
{[1.160]} \\
\{5.48\} \\
\end{array}$ \\
\hline $\begin{array}{l}\text { Panel B: Difference } \\
\text { Regressions, } \\
\text { Corresponding } \\
\text { Specifications in Table } 3\end{array}$ & $\begin{array}{l}\text { Table 3, } \\
\text { Column 1, } \\
\text { OLS }\end{array}$ & $\begin{array}{l}\text { Table 3, } \\
\text { Column 1, } \\
\text { IV }\end{array}$ & $\begin{array}{l}\text { Table 3, } \\
\text { Column 2, } \\
\text { OLS }\end{array}$ & $\begin{array}{l}\text { Table 3, } \\
\text { Column 2, } \\
\text { IV }\end{array}$ & $\begin{array}{l}\text { Table 3, } \\
\text { Column 3, } \\
\text { OLS }\end{array}$ & $\begin{array}{l}\text { Table 3, } \\
\text { Column 3, } \\
\text { IV }\end{array}$ \\
\hline Refrigerators 1940-1950 & $\begin{array}{c}-0.007 \\
{[0.099]}\end{array}$ & $\begin{array}{c}-3.570 \\
{[2.064]} \\
\{3.30\}\end{array}$ & $\begin{array}{c}-0.214 \\
{[0.089]}\end{array}$ & $\begin{array}{c}-0.932 \\
{[0.168]} \\
\{99.77\}\end{array}$ & $\begin{array}{c}-0.101 \\
{[0.094]}\end{array}$ & $\begin{array}{c}-0.573 \\
{[0.192]} \\
\{62.73\}\end{array}$ \\
\hline $\begin{array}{l}\text { State fixed effects } \\
\text { Control variables }\end{array}$ & $\begin{array}{l}\text { No } \\
\text { No }\end{array}$ & $\begin{array}{l}\text { No } \\
\text { No }\end{array}$ & $\begin{array}{l}\text { Yes } \\
\text { No }\end{array}$ & $\begin{array}{l}\text { Yes } \\
\text { No }\end{array}$ & $\begin{array}{l}\text { Yes } \\
\text { Yes }\end{array}$ & $\begin{array}{l}\text { Yes } \\
\text { Yes }\end{array}$ \\
\hline
\end{tabular}

Notes: The table reports both OLS and IV regressions of fertility on appliance ownership, corresponding to tables 2 and 3 in the paper. Robust standard errors are clustered by state and reported in square brackets. In the IV columns, the first-stage regression's F-statistic on the excluded instrument (proportion of households with electrical lights) is reported in curved brackets. The 1960 census did not inquire about electric lights, so the IV approach cannot be attempted for that year. 
Appendix Table 3.5. Regressions with Controls for Proportions of Families with "Low" and "High" Income, 1950 and 1960

\begin{tabular}{lcc}
\hline & $\begin{array}{c}\text { Original coefficients } \\
\text { and standard errors } \\
\text { from “column 3” of } \\
\text { relevant table and panel }\end{array}$ & $\begin{array}{c}\text { After adding } \\
\text { controls for families } \\
\text { with “low” and } \\
\text { "high” income }\end{array}$ \\
\hline Table 2, Panel B: 1950, Refrigerators & -0.401 & -0.413 \\
Table 2, Panel B: 1950, Modern Stoves & $(0.104)$ & $(0.089)$ \\
Table 2, Panel C: 1960, Washing Machine & 0.004 & -0.034 \\
Table 2, Panel C: 1960, Modern Stove & $(0.049)$ & $(0.049)$ \\
& 0.068 & 0.085 \\
Table 4, Panel B: 1950, Electric Lights & $(0.069)$ & $(0.063)$ \\
& -0.309 & -0.291 \\
& $(0.113)$ & $-0.103)$ \\
& -0.375 & $(0.066)$ \\
\hline
\end{tabular}

Notes and sources: See tables 2 and 4 of the paper. 


\section{Additional References}

Gould, William. 1992. “sg11.1: Quantile Regression with Bootstrapped Standard Errors.” Stata Technical Bulletin 9: 19-21.

Gould, William. 1997. “sg70: Interquartile and Simultaneous-Quantile Regression.” Stata Technical Bulletin 38: 14-22.

Koenker, Roger and Gilbert Bassett, Jr. 1982. "Robust Tests for Heteroskedasticity Based on Regression Quantiles.” Econometrica 50: 43-61.

Rogers, William. 1993. “sg11.2: Calculation of Quantile Regression Standard Errors.” Stata Technical Bulletin 13: 18-19. 